\title{
MCP mediated active targeting calcium phosphate hybrid nanoparticles for the treatment of orthotopic drug-resistant colon cancer
}

Shaobo Bai ${ }^{1 \dagger}$, Yang Sun ${ }^{2 \dagger}$, Ying Cheng ${ }^{1}$, Weiliang Ye ${ }^{1}$, Chenchao Jiang ${ }^{1}$, Miao Liu ${ }^{1}$, Qifeng Ji ${ }^{1}$, Bangle Zhang ${ }^{1}$, Qibing Mei ${ }^{2}$, Daozhou Liu' ${ }^{1 *}$ and Siyuan Zhou ${ }^{1,2^{*}}$ (D)

\begin{abstract}
Background: Colon cancer is a most common malignant cancer in digestive system, and it is prone to develop resistance to the commonly used chemotherapy drugs, leading to local recurrence and metastasis. Paris saponin VII (PSVII) could not only inhibit the proliferation of colon cancer cells but also effectively induce apoptosis of drugresistant colon cancer cells and reduce the metastasis of drug-resistant colon cancer cells as well. However, PSVII was insoluble in water and fat. It displayed no selective distribution in body and could cause severe hemolysis. Herein, colon cancer targeting calcium phosphate nanoparticles were developed to carry PSVII to treat drug-resistant colon cancer.

Results: PSVII carboxymethyl- $\beta$-cyclodextrin inclusion compound was successfully encapsulated in colon cancer targeting calcium phosphate nanoparticles (PSVII@MCP-CaP) by using modified citrus pectin as stabilizer agent and colon cancer cell targeting moiety. PSVII@MCP-CaP significantly reduced the hemolysis of PSVII. Moreover, by specific accumulating in orthotopic drug-resistant colon cancer tissue, PSVII@MCP-CaP markedly inhibited the growth of orthotopic drug-resistant colon cancer in nude mice. PSVII@MCP-CaP promoted the apoptosis of drug-resistant colon cancer cells through mitochondria-mediated apoptosis pathway. Moreover, PSVII@MCP-CaP significantly inhibited the invasion and migration of drug-resistant colon cancer cells by increasing E-cadherin protein expression and reducing $\mathrm{N}$-cadherin and MMP-9 protein expression.
\end{abstract}

Conclusion: PSVII@MCP-CaP has great potential in the treatment of drug-resistant colon cancer. This study also explores a new method to prepare active targeting calcium phosphate nanoparticles loaded with a fat and water insoluble compound in water.

Keywords: Paris saponin VII, Modified citrus pectin, Drug-resistant colon cancer, Colon cancer targeting drug delivery system, Calcium phosphate nanoparticles

\footnotetext{
*Correspondence: Idzzhhnxh@163.com; zhousy@fmmu.edu.cn

†Shaobo Bai and Yang Sun contributed equally to the work

${ }^{1}$ Department of Pharmaceutics, School of Pharmacy, Air Force Medical

University, Changle West Road 169, Xi'an 710032, Shaanxi, China

Full list of author information is available at the end of the article
}

(c) The Author(s) 2021. Open Access This article is licensed under a Creative Commons Attribution 4.0 International License, which permits use, sharing, adaptation, distribution and reproduction in any medium or format, as long as you give appropriate credit to the original author(s) and the source, provide a link to the Creative Commons licence, and indicate if changes were made. The images or other third party material in this article are included in the article's Creative Commons licence, unless indicated otherwise in a credit line to the material. If material is not included in the article's Creative Commons licence and your intended use is not permitted by statutory regulation or exceeds the permitted use, you will need to obtain permission directly from the copyright holder. To view a copy of this licence, visit http://creativecommons.org/licenses/by/4.0/. The Creative Commons Public Domain Dedication waiver (http://creativeco mmons.org/publicdomain/zero/1.0/) applies to the data made available in this article, unless otherwise stated in a credit line to the data. 


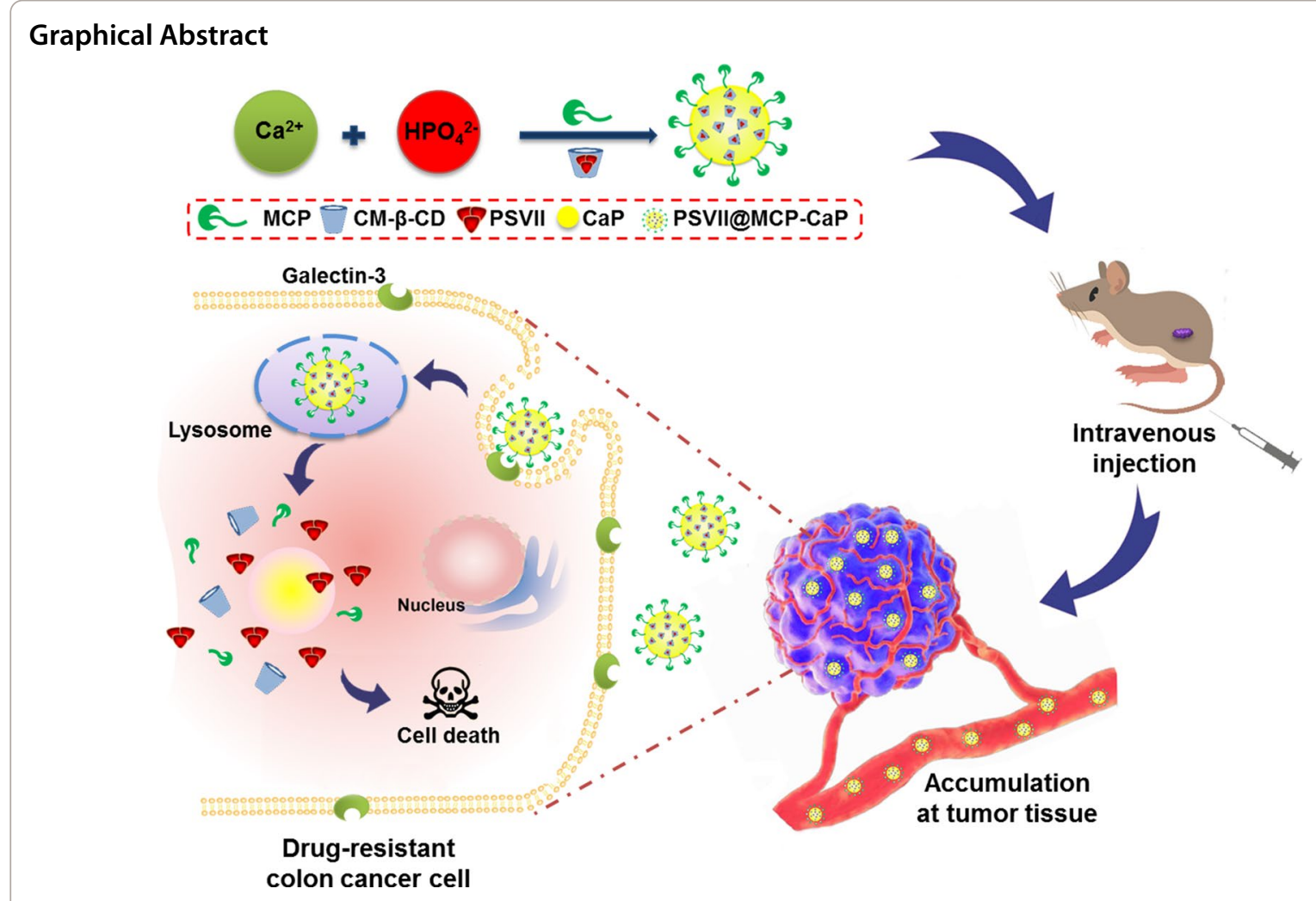

\section{Background}

Colon cancer is a most common malignant cancer in digestive system, which is a serious threat to human health. Global cancer statistics results show that colon cancer ranks third in morbidity and second in mortality, and it causes more than 900,000 deaths each year [1]. At present, the treatment method for colon cancer includes surgical resection, radiotherapy, chemotherapy and their combined application, among which chemotherapy plays an important role in treatment of colon cancer $[2,3]$. The purpose of chemotherapy is to eliminate the small lesions that can't be removed by surgery. At the same time, chemotherapy is also used to reduce local recurrence and metastasis of colon cancer, and finally improve the survival rate. With the use of oxaliplatin and irinotecan, chemotherapy has significantly improved the survival time of colon cancer patients. However, colon cancer cell is prone to develop resistance to commonly used chemotherapy drugs, leading to local recurrence and metastasis, which is the main cause of death in colon cancer patients at present [4]. Therefore, it is an urgent need to find new chemotherapy drugs to treat drug-resistant colon cancer.

In our previous studies, we found that Paris saponin VII (PSVII) could not only inhibit the proliferation of colon cancer cells but also effectively induce apoptosis of drug-resistant colon cancer cells and inhibit the metastasis of drug-resistant colon cancer cells [5]. However, PSVII was insoluble in water and fat. It displayed no selective distribution in body and caused severe hemolysis [6]. These disadvantages limited its application in colon cancer treatment. Thus, construction of an appropriate drug delivery system to deliver PSVII to drugresistant colon cancer cells while reducing its hemolysis effect is the key point for PSVII to inhibit the growth of drug-resistant colon cancer in vivo.

Calcium phosphate nanoparticle (CaP nanoparticles) is an excellent drug delivery system with good safety, biocompatibility and biodegradability [7-9]. CaP nanoparticles, namely amorphous calcium phosphate (ACP), can be formed by $\mathrm{Ca}^{2+}$ and $\mathrm{PO}_{4}{ }^{3-}$ in aqueous solution at room temperature [10]. ACP is metastable and easy to crystallize into calcium phosphate crystals, which significantly reduces its drug loading capacity and greatly limits its application in drug delivery. It was found that some special materials containing carboxyl group and phosphate group, which can bind with $\mathrm{Ca}^{2+}$, could increase the stability of $\mathrm{CaP}$ nanoparticles [11-13]. We found that carboxymethyl- $\beta$-cyclodextrin $(\mathrm{CM}-\beta-\mathrm{CD})$ could effectively encapsulate PSVII to form CM- $\beta-C D$ inclusion compound (PSVII@CM- $\beta-C D$ ), which markedly 


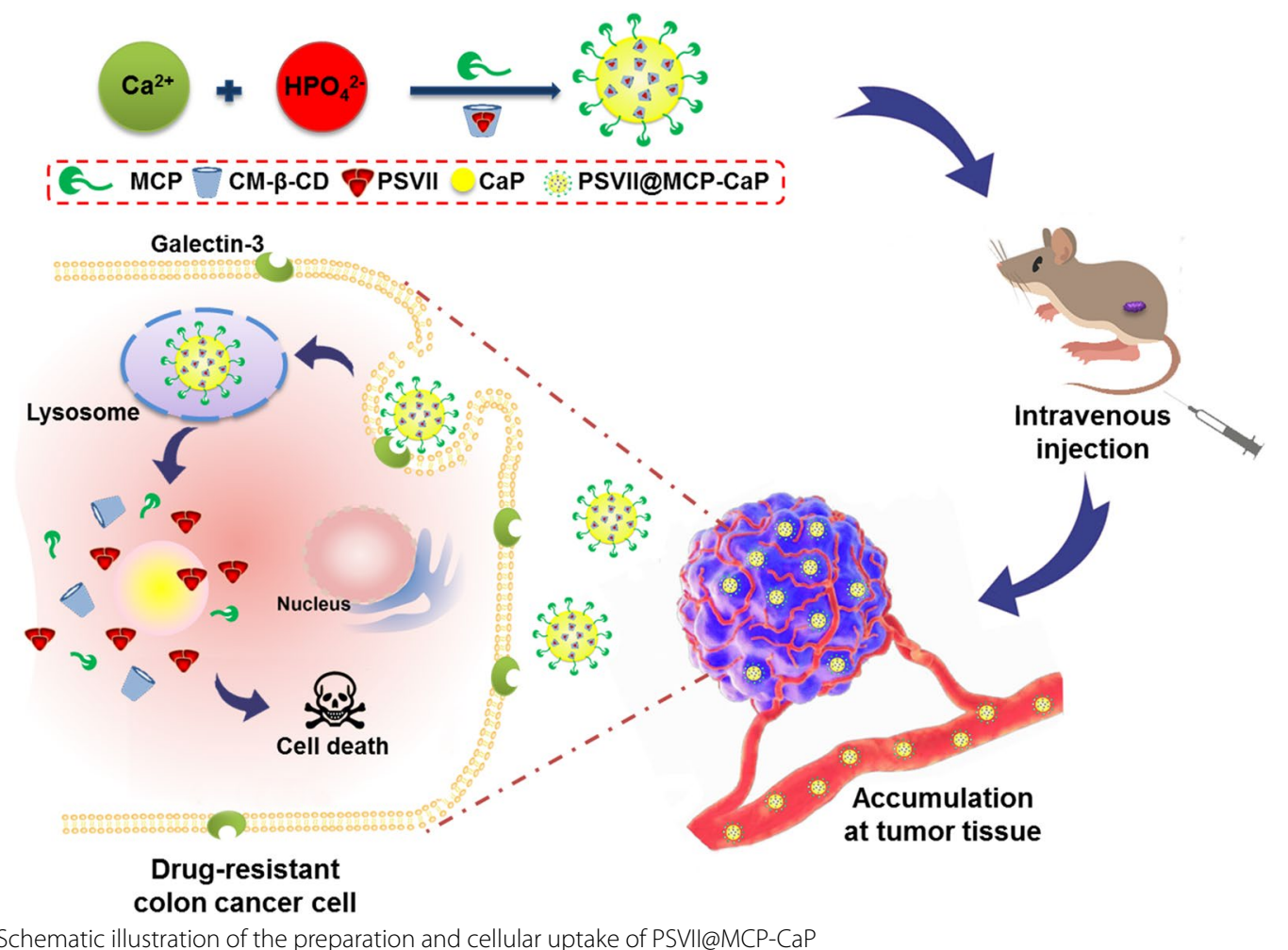

increased the solubility of PSVII in water. Moreover, CM- $\beta-C D$ is able to bind with $\mathrm{Ca}^{2+}$ [14]. In the process of preparing CaP nanoparticles in water, PSVII@CM- $\beta$-CD could not only stabilize $\mathrm{CaP}$ nanoparticles but also realize the embedding of PSVII. However, CaP nanoparticles exhibited low uptake efficiency by cancer cells and no active targeting effect on drug-resistant colon cancer cell, which seriously affects the therapeutic effect of PSVII-encapsulated CaP nanoparticles to colon cancer in vivo. Recently, we found that galectin-3 (Gal-3) highly expressed on the cell membrane of drug-resistant colon cancer cells, and modified citrus pectin (MCP) could selectively bind with Gal-3 [15-17]. Moreover, MCP contains a large number of carboxyl groups, which are able to combine with $\mathrm{Ca}^{2+}$ to reduce the recrystallization of $\mathrm{ACP}$ and improve the stability of $\mathrm{CaP}$ nanoparticles.

In this study, by using PSVII as an anti-cancer drug, CM- $\beta-C D$ as the encapsulating material of PSVII, MCP as a targeting ligand of drug-resistant colon cancer cells, PSVII@CM- $\beta-C D$ and MCP also as stabilizers of $\mathrm{CaP}$ nanoparticles, colon cancer targeting $\mathrm{CaP}$ nanoparticles loading with PSVII (PSVII@MCP-CaP) was prepared (Scheme 1). PSVII@MCP-CaP was supposed to decrease the hemolysis effect of PSVII. At the same time, PSVII@ $\mathrm{MCP}-\mathrm{CaP}$ increased the distribution of PSVII in orthotopic drug-resistant colon cancer tissues and improved the inhibitory effect of PSVII on orthotopic drug-resistant colon cancer.

\section{Materials and methods \\ Materials}

PSVII was purchased from Shanghai Yuanye Biotechnology Co. (Shanghai, China). Modified citrus pectin (MCP) was obtained from Centrax International (USA). Oxaliplatin (L-OHP) and 5-fluorouracil (5-Fu) were purchased from Energy Chemical (Shanghai, China). Carboxymethyl- $\beta$-cyclodextrin $(C M-\beta-C D)$ was obtained from Shandong Binzhou Zhiyuan Biotechnology Co. (Binzhou, China). Paraformaldehyde, 4',6-diamidino-2phenylindole dihydrochloride (DAPI) and 3-(4,5-dimethylthiazol-2-yl)-2,5-diphenyltetrazolium bromide (MTT) were purchased from Xi'an Kehao Biotechnology Co. (Xi'an, China). RPMI-1640 cell culture medium and fetal bovine serum (FBS) were obtained from HyClone (USA). Penicillin-streptomycin mixture and trypsin/EDTA solution were purchased from Solarbio (Beijing, China). Antibodies were obtained from Abcam (USA). The SDSPAGE was purchased from Beyotime (Shanghai, China). HCT116 cell, HT-29 cell, SW620 cell and NCM460 cell were bought from ATCC (USA). 5-Fu-resistant HCT116 cell (HCT116/Fu cell) and L-OHP-resistant HCT116 cell (HCT116/L cell) were obtained from Shanghai Zhewen 
Biotechnology Co. (Shanghai, China). Nude mice and SD rats were purchased from the Experimental Animal Center of Air Force Medical University (Xi'an, China).

\section{Gal-3 expression in normal colon tissue and orthotopic drug-resistant colon cancer tissue}

The normal colon tissue and orthotopic drug-resistant colon cancer tissue were fixed with $4 \%$ paraformaldehyde solution for $24 \mathrm{~h}$, and then they were sliced after being embedded in paraffin. The sections were incubated with Gal-3 antibody for $1 \mathrm{~h}$, and then sections were incubated with PE-labeled secondary antibody for $1 \mathrm{~h}$. Gal-3 in normal colon tissue and orthotopic drug-resistant colon cancer tissue were observed by laser scanning confocal microscopy (LSCM, FV3000, Olypus, Japan).

\section{Detection of Gal-3 expression in normal colon epithelial cell and colon cancer cell}

Normal colon epithelial cell (NCM460 cell) and colon cancer cell (including HCT116 cell, HCT116/F cell, HCT116/L cell, HT-29 cell and SW620 cell) in the logarithmic growth phase were planted in culture dish containing $8 \mathrm{~mL}$ culture medium at density of $1 \times 10^{6}$ cells/ dish. After being cultured for $24 \mathrm{~h}$, the cells were collected and lysed with cell lysate in an ice bath for $30 \mathrm{~min}$. The cell lysate was centrifuged for $15 \mathrm{~min}(13,200 \times g)$, and the supernatant was collected. Western blot was used to detect Gal-3 in the supernatant.

\section{Localization of Gal-3 in normal colon epithelial cell and colon cancer cell}

NCM460 cell, HCT116 cell, HCT116/F cell, HCT116/L cell, HT-29 cell and SW620 cell in logarithmic growth phase was respectively inoculated in cover glass-containing 24-well plate $(500 \mu \mathrm{L} /$ well $)$ with density of $1 \times 10^{4}$ cells $/ \mathrm{mL}$ and was cultured for $24 \mathrm{~h}$. After being rinsed with PBS, the cover glass was fixed with $4 \%$ paraformaldehyde solution for $15 \mathrm{~min}$, and then sealed with 5\% BSA solution for 30 min. Next, Gal-3 primary antibody was added and incubated overnight at $4{ }^{\circ} \mathrm{C}$. The cover glass was incubated with $\mathrm{Cy} 5$-labeled secondary antibody for $1 \mathrm{~h}$ at room temperature. Next, DIO membrane dye solution was incubated with cover glass at room temperature for $30 \mathrm{~min}$. The cover glasses were cleaned with PBS, and then they were incubated with DAPI solution at room temperature for $20 \mathrm{~min}$. Finally, cover glasses were sealed with anti-fluorescence quenching sealing solution, and the localization of Gal-3 in colon cancer cells was observed under LSCM.

\section{Preparation and characterization of PSVII@MCP-CaP}

PSVII $(8.0 \mathrm{mg})$ and CM- $\beta-C D(32.0 \mathrm{mg})$ were dissolved into $4.0 \mathrm{~mL}$ deionized water and stirred for $4 \mathrm{~h}$. MCP
(60 mg) was added into above solution and stirred at room temperature for $10 \mathrm{~min}$. Then, $500 \mu \mathrm{L}$ of $\mathrm{CaCl}_{2}$ and $\left(\mathrm{NH}_{4}\right)_{2} \mathrm{HPO}_{4}$ solution were slowly added and stirred at $80{ }^{\circ} \mathrm{C}$ for $1 \mathrm{~h} .40 \mathrm{~mL}$ deionized water was added into the mixture solution, and ultrasound was applied for $3 \mathrm{~min}$. Next, $0.45 \mu \mathrm{m}$ microporous filtration membrane was used to filter the mixture solution. Finally, PSVII@MCP$\mathrm{CaP}$ powder was obtained after lyophilization of filtrate. By using Cy7.5 labelled PSVII (Cy7.5-PSVII), Cy7.5PSVII@MCP-CaP was prepared with the same method in the preparation of PSVII@MCP-CaP. Sulfur labeled PSVII was obtained by modifying PSVII with 3-mercaptopropionic acid. Then, sulfur labeled PSVII was encapsulated in $\mathrm{CaP}$ nanoparticle by using the same method in the preparation of PSVII@MCP-CaP. Blank nanoparticle (without PSVII, @MCP-CaP) was prepared by using the same method in the preparation of PSVII@MCP-CaP. Particle size, stability and zeta potential of PSVII@MCP$\mathrm{CaP}$ were measured by zeta potential and nanoparticle analyzer (Delsa Nano C, Beckman, USA).

The appearance of PSVII@MCP-CaP was observed by transmission electron microscope (TEM, Tecnai G2 Spirit, FEI, USA). The encapsulation of sulfur labeled PSVII in CaP nanoparticle was investigated by element mapping analysis. The drug loading and drug release characteristics of PSVII@MCP-CaP were determined by high performance liquid chromatograph (HPLC, Waters 2695/2996, USA). Briefly, PSVII@MCP-CaP (30 mg) was dispersed in PBS (pH5.0 and pH7.4) at concentration of $6 \mathrm{mg} / \mathrm{mL}$. The PSVII@MCP-CaP solution was transferred into a dialysis bag with an interception molecular weight of $5000 \mathrm{Da}$. Then dialysis bag was immerged in the same release medium $(60 \mathrm{~mL})$ as that in dialysis bag. $0.5 \mathrm{~mL}$ of the release medium out of dialysis bag was taken out at different time point, and $0.5 \mathrm{~mL}$ of the corresponding fresh release medium was added into the solution out of dialysis bag. The concentration of PSVII in release medium was determined by HPLC, and the cumulative release amount was calculated. The drug release curve was plotted.

Waters Symmetry $\mathrm{C}_{18}(50 \mathrm{~mm} \times 2.1 \mathrm{~mm}, 5 \mu \mathrm{m})$ was used as analytic column. Acetonitrile and water ( $\mathrm{v}: \mathrm{v}=50: 50)$ was used as mobile phase. The flow rate was $1 \mathrm{~mL} / \mathrm{min}$. The column temperature was $25{ }^{\circ} \mathrm{C}$. The detection wavelength was $203 \mathrm{~nm}$. The equation of the standard curve was $Y=136.66 X+97.13, \mathrm{R}^{2}=0.9999$.

\section{Hemolysis analysis}

$10 \mathrm{~mL}$ rat whole blood was diluted with $100 \mathrm{~mL}$ normal saline. The mixture was slightly shaken and centrifuged for $5 \mathrm{~min}$ (3000 rpm). Red blood cells were collected and washed with normal saline for 3 times. Red blood cells were collected. $1 \%$ red blood cell suspension was 
prepared with normal saline as the dispersion medium. Then, $100 \mu \mathrm{L} @ \mathrm{MCP}-\mathrm{CaP}$ solution, PSVII solution, PSVII@MCP-CaP solution and normal saline were added into $5 \mathrm{~mL}$ red blood cell suspension, respectively. The mixture was incubated in $37{ }^{\circ} \mathrm{C}$ water bath for $40 \mathrm{~min}$. The mixture was centrifuged for $5 \mathrm{~min}$ at $4{ }^{\circ} \mathrm{C}(3000 \mathrm{rpm})$, then supernatant and red blood cells were separated. (1) Red blood cells were dispersed into $2 \mathrm{~mL}$ glutaraldehyde solution and fixed for $2 \mathrm{~h}$. Then it was dehydrated by successively using $10 \%, 20 \%, 40 \%, 80 \%$ and $90 \%$ alcohol for $10 \mathrm{~min}$ each time. The dehydrated red blood cells were dispersed into anhydrous ethanol. Finally, the red blood cells were dropped onto the slide and dried at room temperature for $2 \mathrm{~h}$. The morphology of red blood cells was observed by scanning electron microscope (SEM, Hitachi, S4800, Japan). (2) The absorbance of the supernatant at $414 \mathrm{~nm}$ was measured with an ultraviolet spectrophotometer, and the hemolysis rate (HR) was calculated. HR $(\%)=($ absorbance of sample - absorbance of negative control)/(absorbance of positive control-absorbance of negative control) $\times 100 \%$.

\section{X-ray photoelectron spectroscopy analysis and thermogravimetric analysis}

The surface elements of PSVII@MCP-CaP were determined by X-ray photoelectron spectrometer (ESCALAB250Xi, Thermo Fisher Scientific, USA). The scanning times were 10. The excitation source was $\mathrm{Al} \mathrm{Ka} \mathrm{X-ray,}$ and the analysis point area was $650 \mu \mathrm{m}$. The analyzer mode was CAE. The band pass energy was $20.0 \mathrm{eV}$, and the analysis energy step was $0.05 \mathrm{eV}$.

Calcium phosphate powder (CaP powder, $5 \mathrm{mg}$ ), @ MCP-CaP (5 mg), PSVII@MCP-CaP (5 mg) and MCP $(5 \mathrm{mg})$ were put into crucible, respectively. DTG thermogravimetric analyzer (DSC-03, PerkinElmer, USA) was used for comprehensive thermal analysis. The scanning temperature was $0-500{ }^{\circ} \mathrm{C}$. The protective gas was nitrogen, and heating rate was $10^{\circ} \mathrm{C} / \mathrm{min}$.

\section{Cellular uptake experiment}

HCT116/L cells in logarithmic growth phase were inoculated into 24 -well plate $(500 \mu \mathrm{L} /$ well $)$ with cover glass at density of $1 \times 10^{4}$ cells $/ \mathrm{mL}$ and cultured for $24 \mathrm{~h}$. The culture medium was replaced with serum-free fresh medium containing Cy7.5-PSVII@MCP-CaP, and the amount of PSVII in per well was $2 \mu \mathrm{mol}$ and $5 \mu \mathrm{mol}$. After cells were cultured for $0.5 \mathrm{~h}, 2 \mathrm{~h}$ and $4 \mathrm{~h}$, the cover glass was fixed with $4 \%$ paraformaldehyde solution for $15 \mathrm{~min}$. Next, the cover glass was stained by $1 \mathrm{~mL}$ DAPI solution (600 ng/ $\mathrm{mL}$ ) for $15 \mathrm{~min}$. The cover glasses were cleaned with PBS and sealed with glycerin. Finally, the fluorescence in HCT116/L cells was observed by LSCM.
HCT116/L cells in logarithmic growth phase were seeded into 24 well plates $(500 \mu \mathrm{L} /$ well $)$ with cover glass at density of $1 \times 10^{4}$ cells $/ \mathrm{mL}$ and cultured for $24 \mathrm{~h}$. The culture medium was replaced with serum-free fresh culture medium containing $\mathrm{MCP}(12.5,6.25,3.125 \mu \mathrm{g} / \mathrm{mL})$ and cultured for $1 \mathrm{~h}$. Then, Cy7.5-PSVII@MCP-CaP was added into cell culture medium. After cells were cultured for $4 \mathrm{~h}$, the cover glass was fixed with $4 \%$ paraformaldehyde solution for $15 \mathrm{~min}$. Next, $1 \mathrm{~mL}$ DAPI solution $(600 \mathrm{ng} / \mathrm{mL})$ was used to stain cell nucleus on cover glass for $15 \mathrm{~min}$. The cover glass was cleaned with PBS and sealed with glycerin. Finally, the fluorescence in HCT116/L cells was observed by LSCM.

HCT116 cells and HCT116/L cells in logarithmic growth phase were inoculated in 24-well plates containing agarose gel (cell density was $1 \times 10^{3}$ cells/well), and culture medium was replaced by fresh culture medium every other day. When the diameter of cell spheres reached 100-200 $\mu \mathrm{m}$, the cell culture medium was replaced with fresh cell culture medium containing Cy7.5-PSVII@MCP-CaP (equivalent PSVII concentration was $1.0 \mu \mathrm{mol} / \mathrm{L}$ ). After incubation for $2 \mathrm{~h}$, the cell culture medium was removed, and 4\% paraformaldehyde solution was used to fix cell spheres. The distribution of fluorescence in colon cancer cell spheres was observed by LSCM.

HCT116/L cells in logarithmic growth phase were planted into 24 well plates $(500 \mu \mathrm{L} /$ well $)$ with cover glass at density of $1 \times 10^{4}$ cells $/ \mathrm{mL}$ and cultured for $24 \mathrm{~h}$. After pretreatment with sucrose (clathrin endocytosis inhibitor), 2-deoxy-D-glucose (ATP depletion agent), colchicine (macropinocytosis inhibitor) and methyl- $\beta$-cyclodextrin (caveolin endocytosis inhibitor) for $1 \mathrm{~h}$, fresh cell culture medium containing Cy7.5-PSVII@MCP-CaP was added and cultured for $4 \mathrm{~h}$. The cover glass was fixed with $4 \%$ paraformaldehyde solution for $15 \mathrm{~min}$, and then DAPI solution $(600 \mathrm{ng} / \mathrm{mL})$ was used to stain cell nucleus on cover glass for $15 \mathrm{~min}$. Finally, the cover glass was cleaned with PBS and sealed with glycerin. The fluorescence in HCT116/L cells was observed by LSCM.

\section{Cytotoxicity test}

MTT assay was used to detect the cytotoxicity of PSVII@MCP-CaP on colon cancer cells. HCT116 cell, HCT116/L cell, HT-29 cell and SW620 cell at logarithmic growth phase were inoculated into 96-well plate at density of $5 \times 10^{4}$ cells $/ \mathrm{mL}$ ( $200 \mu \mathrm{L} /$ well) and cultured for $24 \mathrm{~h}$. The cell culture medium was replaced with $200 \mu \mathrm{L}$ fresh cell culture medium containing PSVII, L-OHP and PSVII@MCP-CaP, and cells were cultured for $24 \mathrm{~h}$. MTT solution $(20 \mu \mathrm{L}, 5 \mathrm{mg} / \mathrm{mL})$ was added into each well, and cells were incubated for $4 \mathrm{~h}$. After removing cell culture medium, $150 \mu \mathrm{L}$ DMSO was added into each well. The 
absorbance of each well was measured at $490 \mathrm{~nm}$. The inhibition rate was calculated as follows: inhibition rate $\%=[1-($ absorbance of drug treatment group - absorbance of the blank group)/(absorbance of the control group - absorbance of the blank group)] $\times 100 \%$.

Live/dead cell staining was also used to investigate the cytotoxicity of PSVII@MCP-CaP on colon cancer cells. HCT116 cell, HCT116/L cell, HT-29 cell and SW620 cell at logarithmic growth phase were inoculated into 6-well plate at density of $5 \times 10^{5}$ cells $/ \mathrm{mL}(2 \mathrm{~mL} /$ well $)$ and cultured for $24 \mathrm{~h}$. The cell culture medium was replaced with fresh cell culture medium containing PSVII, L-OHP and PSVII@MCP-CaP, the drug concentration was $3 \mu \mathrm{mol} / \mathrm{L}$. Cells were cultured for $48 \mathrm{~h}$. The adherent cells were prepared into suspension and washed twice with assay buffer. Then $1 \mathrm{~mL}$ live/dead staining solution was added to disperse the cells, and the cells were incubated at $37{ }^{\circ} \mathrm{C}$ for $20 \mathrm{~min}$. The cells were washed with assay buffer for 2 times, and then $0.5 \mathrm{~mL}$ PBS was added to disperse the cells. Finally, the living and dead cells was observed under fluorescence microscope.

\section{Clone formation experiment}

HCT116 cells and HCT116/L cells at logarithmic growth phase were inoculated into 6-well plates at density of 200 cells/well and cultured for $24 \mathrm{~h}$. The cell culture medium was replaced with $2 \mathrm{~mL}$ of fresh cell culture medium containing PSVII and PSVII@MCP-CaP (equivalent PSVII concentration was 0.5 and $1 \mu \mathrm{mol} / \mathrm{L}$ ). After incubation for $24 \mathrm{~h}$, the cell culture medium was replaced with fresh drug-free cell culture medium. The cells were observed daily, and cell culture medium was replaced with fresh drug-free cell culture medium every other day. The culture was terminated when multiple clones were visible. The supernatant was removed, and cell clones were fixed with $4 \%$ paraformaldehyde solution for 15 min. Then $0.1 \%$ crystal violet was added to stain cell clones for $15 \mathrm{~min}$. After that, PBS was used to wash cell clones. After drying of cell clones, the number of clones was counted under microscope, and the clone formation rate was calculated. Clone formation rate $=$ (number of clones/number of inoculated cells) $\times 100 \%$.

\section{Migration experiment}

HCT116 cell, HCT116/L cell, HT-29 cell and SW620 cell in logarithmic growth phase were inoculated into donor chamber of 24-well transwell chamber at density of $4 \times 10^{4}$ cells/well, and $600 \mu \mathrm{L}$ RPMI-1640 culture medium containing 30\% fetal bovine serum was added into recipient chamber. After cells were cultured for $6 \mathrm{~h}$, cell culture medium containing PSVII, PSVII@MCP-CaP (equivalent PSVII concentration was 0.5 and $1 \mu \mathrm{mol} / \mathrm{L}$ ) was added into donor chamber, respectively. After cells were cultured for $24 \mathrm{~h}$, transwell chambers were taken out and fixed with $4 \%$ paraformaldehyde solution for $15 \mathrm{~min}$. Then, $0.1 \%$ crystal violet was added into transwell chambers to stain migrated cells for $10 \mathrm{~min}$. After being rinsed with PBS for 3 times, transwell chamber was placed under a microscope and photographed. Next, $800 \mu \mathrm{L}$ of $33 \%$ glacial acetic acid solution was added into the transwell chamber, and the absorbance of glacial acetic acid solution at $570 \mathrm{~nm}$ was measured. Finally, the relative migration rate was calculated. The relative migration rate $(\%)=($ absorbance of drug treatment group/ absorbance of the control group) $\times 100 \%$.

\section{Invasion experiment}

Matrigel was diluted with RPMI-1640 medium precooled at $4{ }^{\circ} \mathrm{C}$ (cell culture medium:matrigel $=9: 1$ ) on an ice bath. $100 \mu \mathrm{L}$ diluted matrigel was added into donor chamber of 24-well plate and incubated at $37{ }^{\circ} \mathrm{C}$ for $2 \mathrm{~h}$ to coagitate matrigel fully. HCT116 cell, HCT116/L cell, HT-29 cell and SW620 cell in logarithmic growth phase were seeded into donor chamber of 24-well plate containing matrigel at density of $4 \times 10^{4}$ cells/well. $400 \mu \mathrm{L}$ RPMI1640 medium containing 30\% fetal bovine serum was added into recipient chamber. After cells were cultured for $6 \mathrm{~h}$, cell culture medium containing PSVII, PSVII@ MCP-CaP (equivalent PSVII concentration was 0.5 and $1 \mu \mathrm{mol} / \mathrm{L}$ ) were added into donor chamber, respectively. After being cultured for $24 \mathrm{~h}$, transwell chambers were taken out and fixed with $4 \%$ paraformaldehyde solution for $15 \mathrm{~min}$. Then, $0.1 \%$ crystal violet was added into transwell chambers to stain invaded cell nucleus for $10 \mathrm{~min}$. After being rinsed with PBS for 3 times, transwell chamber was placed under a microscope and photographed. Next, $800 \mu \mathrm{L}$ of $33 \%$ glacial acetic acid solution was added into the transwell chamber, and the absorbance of glacial acetic acid solution at $570 \mathrm{~nm}$ was measured. Finally, the relative invasion rate was calculated. The relative invasion rate $(\%)=($ absorbance of drug treatment group/absorbance of the control group) $\times 100 \%$.

\section{D drug-resistant colon cancer cell sphere experiment}

HCT116 cells and HCT116/L cells at logarithmic growth phase were inoculated into 24 -well plates containing agarose gel $(500 \mu \mathrm{L} /$ well $)$ at density of $1 \times 10^{3}$ cells/well. The cell culture medium was replaced by fresh cell culture medium every other day. After incubation for 2 weeks, the formation and growth of colon cancer cell spheres were observed. When the cell sphere diameter was about $200 \mu \mathrm{m}, 500 \mu \mathrm{L}$ fresh cell culture medium containing PSVII $(1.0 \mu \mathrm{mol} / \mathrm{L})$ and PSVII@MCP-CaP (equivalent PSVII concentration was $1 \mu \mathrm{mol} / \mathrm{L})$ were added, respectively. After incubation for $24 \mathrm{~h}$, cell culture medium was replaced with fresh drug-free cell culture medium. On 
day 1, 3, 5, 7 and 9 after drug treatment, the growth of cell spheres was observed by microscope. The cell sphere volume was calculated as $\mathrm{V}$ (volume) $=($ long diameter $\times$ short diameter $\left.^{2}\right) / 2$.

\section{Apoptosis-related proteins and invasion-related proteins in drug-resistant colon cancer cells}

HCT116 cell, HCT116/L cell, HT-29 cell and SW620 cell in logarithmic growth phase were inoculated in 6-well plates at density of $1 \times 10^{6}$ cells $/ \mathrm{mL}$ and cultured for $24 \mathrm{~h}$. The cell culture medium was replaced with $2 \mathrm{~mL}$ fresh cell culture medium containing PSVII $(0.5$ and $1 \mu \mathrm{mol} / \mathrm{L})$ and PSVII@MCP-CaP (equivalent PSVII concentration was 0.5 and $1 \mu \mathrm{mol} / \mathrm{L}$ ), respectively. After incubation for $24 \mathrm{~h}$, the total proteins of cells were extracted. The apoptosis-related proteins and invasion-related proteins in cell lysates were detected by western blot.

\section{Orthotopic drug-resistant colon cancer model}

Luciferase labeled oxaliplatin-resistant human colon cancer cells (HCT116/L-Luc) were re-suspended in serumfree medium and inoculated subcutaneously in the back of 5 -week-old nude mice $\left(200 \mu \mathrm{L} /\right.$ mouse, $2 \times 10^{7}$ cells/ $\mathrm{mL}$ ). When the diameter of subcutaneous cancer was about $1-1.5 \mathrm{~cm}$, the nude mice were anesthetized, and cancer tissue was stripped from the subcutaneous tissue under sterile conditions. The cancer tissue was cut into small pieces with a diameter of $1 \mathrm{~mm}$.

5-week-old nude mice were anesthetized and dissected along the right midline of the abdomen to expose the colon. The serous membrane layer of the colon was cut at the site with abundant blood supply on the surface of the colon (about $1 \mathrm{~cm}$ away from the cecum), and then the sterile small curved forceps were used to push the incision inwardly to form a local groove. The pre-cut cancer tissue was placed in the groove, and 2-3 drops of $\mathrm{OB}$ biological glue were dropped to fix tumor tissue. The colon was reset, and incision was sutured with sterile silk thread. Three days later, luciferase substrate was intraperitoneally injected to the mice $(150 \mathrm{mg} / \mathrm{kg})$, the orthotopic colon cancer growth was observed by in vivo imaging (Caliper IVIS Lumina II, Siemens, Germany).

\section{Biodistribution of PSVII@MCP-CaP in orthotopic drug-resistant colon cancer nude mice}

On the 10th day after orthotopic drug-resistant colon cancer model was successful set up, Cy7.5-PSVII $(5 \mathrm{mg} /$ $\mathrm{kg}$ ) and Cy7.5-PSVII@MCP-CaP (equivalent Cy7.5-PSVII concentration was $5 \mathrm{mg} / \mathrm{kg}$ ) were injected by the tail vein of nude mice. The brain, heart, liver, spleen, lung, kidney and colon cancer tissue of nude mice were isolated at $12 \mathrm{~h}$ and $24 \mathrm{~h}$. The distribution of fluorescence in orthotopic colon cancer tissue and normal organs of nude mice was observed by in vivo bioluminescence imaging. Next, the brain, heart, liver, spleen, lung, kidney and tumor tissues were placed in a glass grinder, and RIPA lysate $(200 \mu \mathrm{L} / 100 \mathrm{mg}$ tissue) was added. The tissues were thoroughly ground in ice bath. The homogenate was centrifuged at $4{ }^{\circ} \mathrm{C}$ for $15 \mathrm{~min}(13,200 \times g)$ to obtain the supernatant. Finally, fluorescence intensity in supernatant of brain, heart, liver, spleen, lung, kidney and tumor tissue was measured by fluorescence spectrophotometer.

\section{The inhibitory effect of PSVII@MCP-CaP on the growth of orthotopic drug-resistant colon cancer in nude mice} On the 4th day after orthotopic drug-resistant colon cancer model was set up, luciferase substrate was intraperitoneally injected to mice $(150 \mathrm{mg} / \mathrm{kg})$, the orthotopic colon cancer growth was observed by in vivo bioluminescence imaging. The unqualified nude mice were removed, and the remaining orthotopic drug-resistant colon cancer nude mice were divided into four groups. The fluorescence intensity of orthotopic colon cancer tissues in each group showed no significant difference. The cancerbearing nude mice were given normal saline, oxaliplatin $(5 \mathrm{mg} / \mathrm{kg})$, PSVII $(5 \mathrm{mg} / \mathrm{kg})$ and PSVII@MCP-CaP ( $5 \mathrm{mg} / \mathrm{kg}$, equivalent of PSVII) by tail vein injection every 4 days. After 7 times of drug administration, the experiment was terminated. Luciferase substrate was intraperitoneally injected into mice $(150 \mathrm{mg} / \mathrm{kg})$, and the growth of orthotopic colon cancer tissue was observed by in vivo imaging. The colon of nude mice was isolated and photographed. The weight and size of colon cancer tissue was measured. Colon cancer tissue, brain, heart, liver, spleen, lung and kidney of nude mice were isolated and fixed with $4 \%$ paraformaldehyde solution. H\&E staining was used to observe the histological morphology of colon cancer tissue and normal tissue. The apoptosis-related proteins and invasion-related proteins in colon cancer tissue were detected by western blot.

\section{Statistical analysis}

Data are expressed as the mean \pm standard deviation (SD). The statistics analysis was performed by using a one-way ANOVA method. $p<0.05$ was considered statistically significant.

\section{Results}

Expression of Gal-3 in drug-resistant colon cancer tissue and colon cancer cells

Immunofluorescence staining results showed that a larger amount of Gal-3 was expressed in drug-resistant colon cancer tissue than in normal colon tissue (Fig. 1A, B; Additional file 1: Fig. S1). Western blot results indicated that in comparison with normal colon epithelial cells (NCM460 cells), Gal-3 protein expression was 

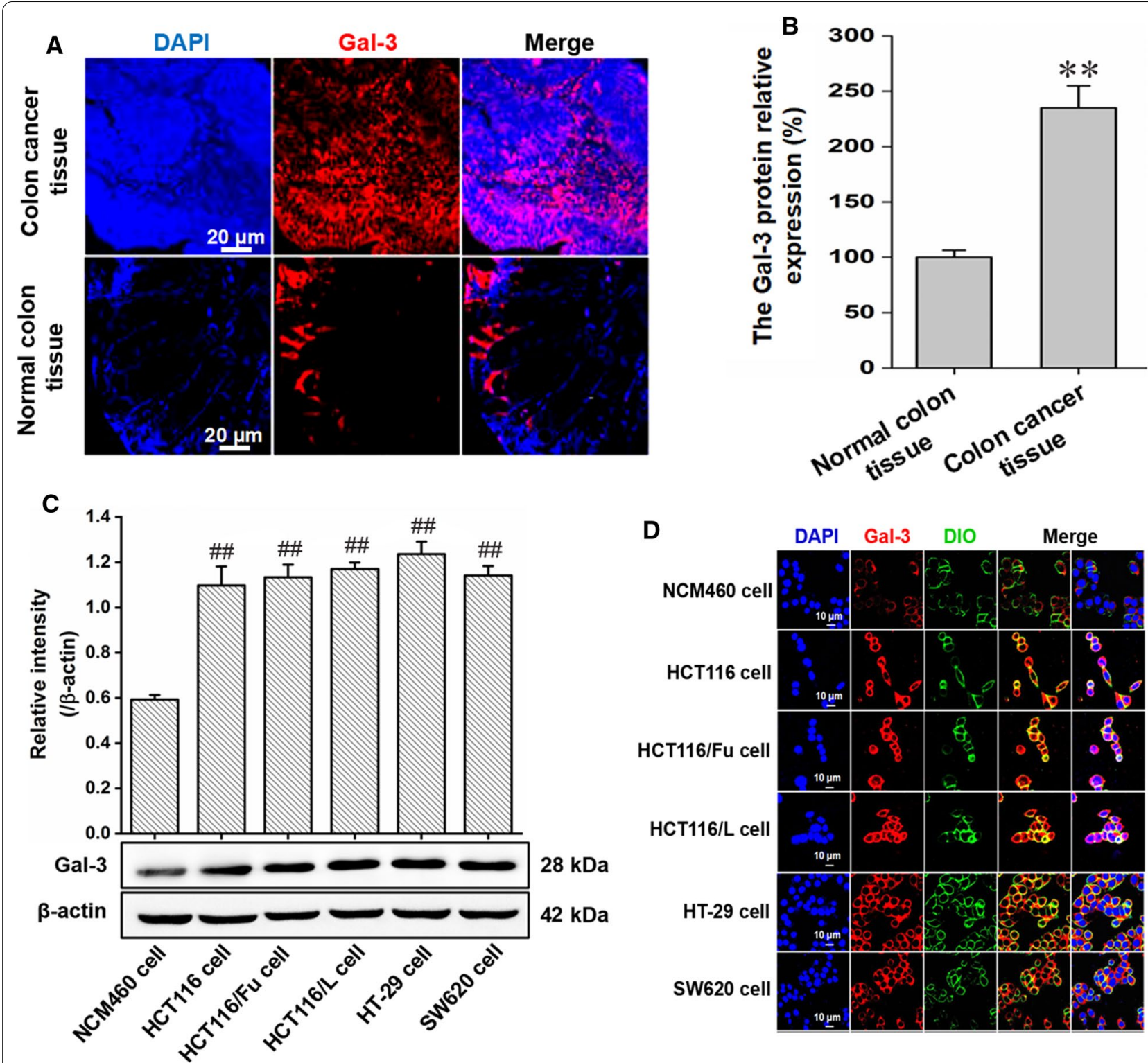

Fig. 1 The expression of Gal-3 in vitro and in vivo. A Expression of Gal-3 in drug-resistant colon cancer tissue and normal colon tissue of mice. B Semi-quantitative statistical results of Gal-3 expression in drug-resistant colon cancer tissue and normal colon tissue. C The expression of Gal-3 in NCM460 cell, HCT116 cell, HCT116/Fu cell, HCT116/L cell, HT-29 cell and SW620 cell detected by western blot. D The distribution of Gal-3 in NCM460 cell, HCT116 cell, HCT116/Fu cell, HCT116/L cell, HT-29 cell and SW620 cell observed by LSCM. All data are expressed as mean \pm SD ( $n=3)$. ${ }^{* *} p<0.01$ vs normal colon tissue; $\#<0.01$ vs NCM460 cell

significantly increased in colon cancer cell line such as HCT116 cell, HCT116/Fu cell, HCT116/L cell, HT-29 cell and SW620 cell (Fig. 1C). In addition, LSCM results showed a large amount of red fluorescence localized on the cell membrane of HCT116 cell, HCT116/Fu cell, HCT116/L cell, HT-29 cell and SW620 cell (Fig. 1D), indicating that Gal-3 highly expressed on the cell membrane of colon cancer cell.

\section{Characterization of PSVII@MCP-CaP}

The average hydration particle size and the average zeta potential of PSVII@MCP-CaP were 104 nm and $-29.62 \mathrm{mV}$, respectively (Fig. 2A, B). TEM results showed that the appearance of PSVII@MCP-CaP was spherical with good dispersion (Fig. 2C). The X-ray photoelectron spectroscopy (XPS) results indicated that PSVII@MCP-CaP contained calcium, phosphorus, 


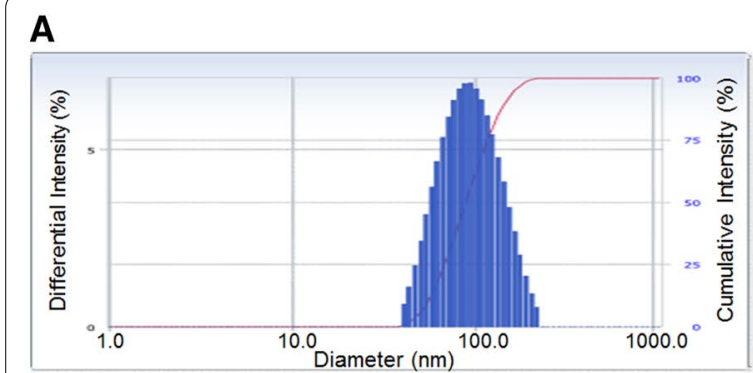

B

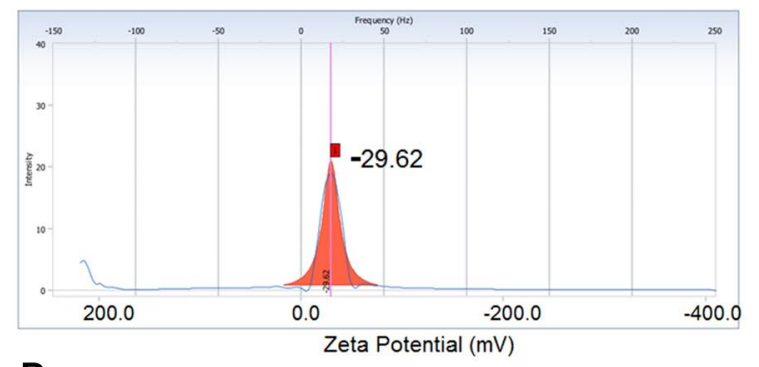

D
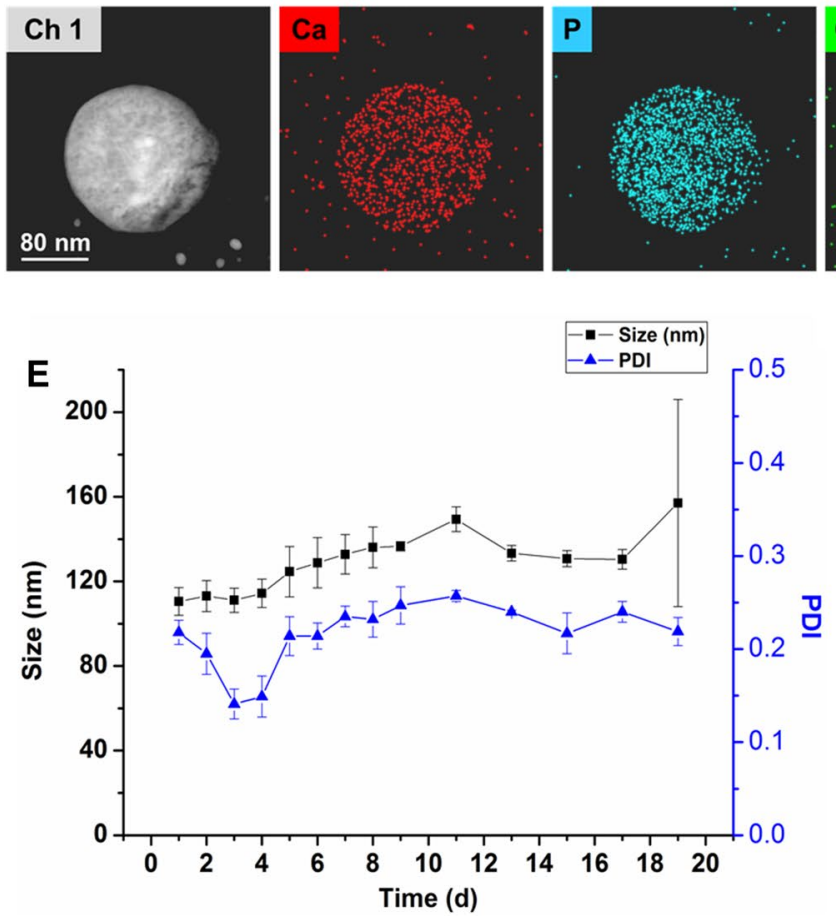

C
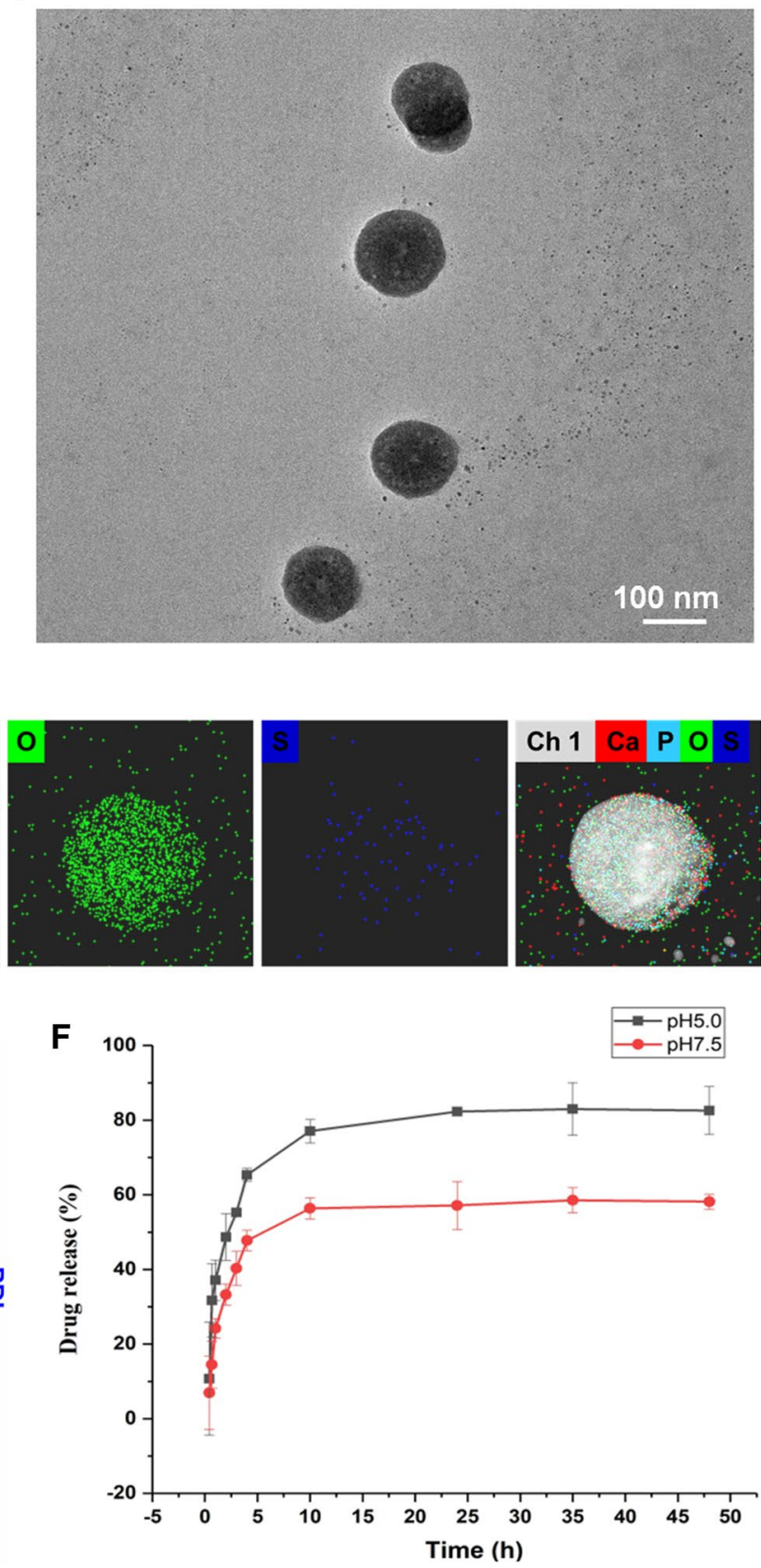

Fig. 2 Characterization of PSVII@MCP-CaP. A Particle size distribution of PSVII@MCP-CaP. B Zeta potential of PSVII@MCP-CaP.CTEM image of PSVII@ MCP-CaP. D Element mapping analysis of MCP-CaP nanoparticles encapsulated with sulfur-labeled PSVII. E Stability of PSVII@MCP-CaP in deionized water. $\mathbf{F}$ In vitro drug release of PSVII@MCP-CaP. All data are expressed as mean \pm SD $(n=3)$

carbon and oxygen (Additional file 1: Fig. S2). The DTG results are showing in Additional file 1: Fig. S3. Pure calcium phosphate powder (CaP powder) had a major weight loss around $160-300{ }^{\circ} \mathrm{C}$, and the peak of DTG was sharp and narrow. The main weight loss range of MCP was $150-350{ }^{\circ} \mathrm{C}$. Meanwhile, the main peak of DTG had bifurcation and trailing, and the peak was relatively wide. This may be caused by the absence of a fixed melting point of MCP. PSVII@CM- $\beta-C D$ inclusion compound mainly loosed weight around $300-450{ }^{\circ} \mathrm{C}$, and its peak shape was wide. Compared with CaP, @MCP$\mathrm{CaP}$ showed a similar initial temperature of weight loss, 
but weight loss rate slowed down and weight loss range increased to around $350{ }^{\circ} \mathrm{C}$. The main peak of DTG widened with tails and the overall percentage of weight loss increased, indicating that $\mathrm{CaP}$ nanoparticles had been modified by MCP. Compared with @MCP-CaP, PSVII@ $\mathrm{MCP}-\mathrm{CaP}$ showed obvious double peaks in DTG. The peak position of the big peak was basically consistent with that of PSVII@CM- $\beta-C D$, and the peak position of the late small peak was consistent with that of PSVII, which was speculated to be caused by PSVII loading. The above results indicated that PSVII@MCP-CaP contained calcium phosphate, PSVII and MCP. Furthermore, the element mapping analysis showed that sulfur-labeled PSVII mainly located in the interior of MCP-CaP nanoparticles (Fig. 2D). This indicated that PSVII was successfully encapsulated in MCP-CaP nanoparticle.

The stability results showed that particle size and PDI of PSVII@MCP-CaP in aqueous solution did not change significantly within 18 days (Fig. 2E), indicating that PSVII@MCP-CaP was relatively stable within 18 days. Besides, the drug loading of PSVII in PSVII@MCP-CaP was $5.12 \%$, and MCP content in PSVII@MCP-CaP was $5.43 \%$. The encapsulation rate of PSVII was $83.2 \%$. Moreover, PSVII released from PSVII@MCP-CaP displayed a $\mathrm{pH}$-sensitive manner. In $\mathrm{pH} 7.5$ release medium, the cumulative drug release was $40 \%$ and $57 \%$ within $3 \mathrm{~h}$ and
$24 \mathrm{~h}$, respectively. In $\mathrm{pH} 5.0$ release medium, the cumulative drug release was $55 \%$ and $82 \%$ within $3 \mathrm{~h}$ and $24 \mathrm{~h}$ (Fig. 2F), respectively.

The effect of PSVII@MCP-CaP on morphological characteristics of erythrocyte membrane is showing in Fig. 3A. The erythrocyte membrane in normal saline treated and @MCP-CaP treated group was intact. PSVII@MCP-CaP had little effect on red blood cell, and there was no obvious red blood cell fragment. PSVII obviously destroyed the red blood cell membrane, and there were a large number of red blood cell fragments. The hemolysis effect of PSVII@MCP-CaP is showing in Fig. 3B, C. The results showed that hemolysis effect of PSVII was very strong, and the hemolysis effect PSVII@ MCP-CaP was significantly lower in comparison with PSVII. These results demonstrated that PSVII@MCP$\mathrm{CaP}$ markedly reduced damage of erythrocyte membrane caused by PSVII.

\section{The uptake of PSVII@MCP-CaP by drug-resistant colon cancer cells}

As shown in Fig. 4A, B, with the increase of incubation time and the concentration of PSVII@MCP-CaP, the red fluorescence intensity in HCT116/L cells was gradually enhanced, indicating the uptake of PSVII@MCP$\mathrm{CaP}$ by HCT116/L cells was gradually increased. These

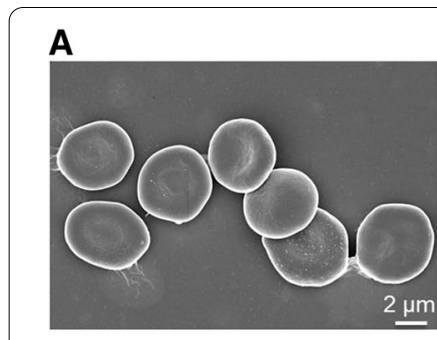

Normal saline

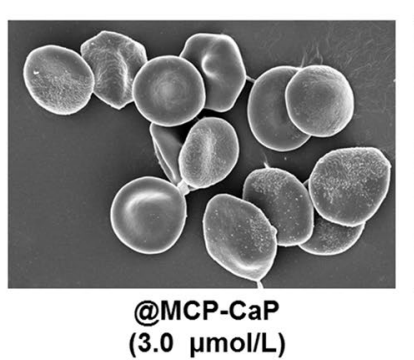

(3.0 $\mu \mathrm{mol} / \mathrm{L})$

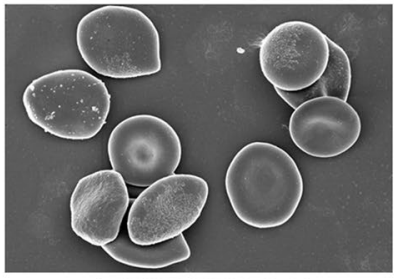

PSVII@MCP-CaP (3.0 $\mu \mathrm{mol} / \mathrm{L})$

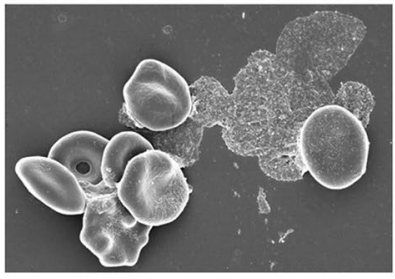

PSVII (3.0 $\mu \mathrm{mol} / \mathrm{L})$

B
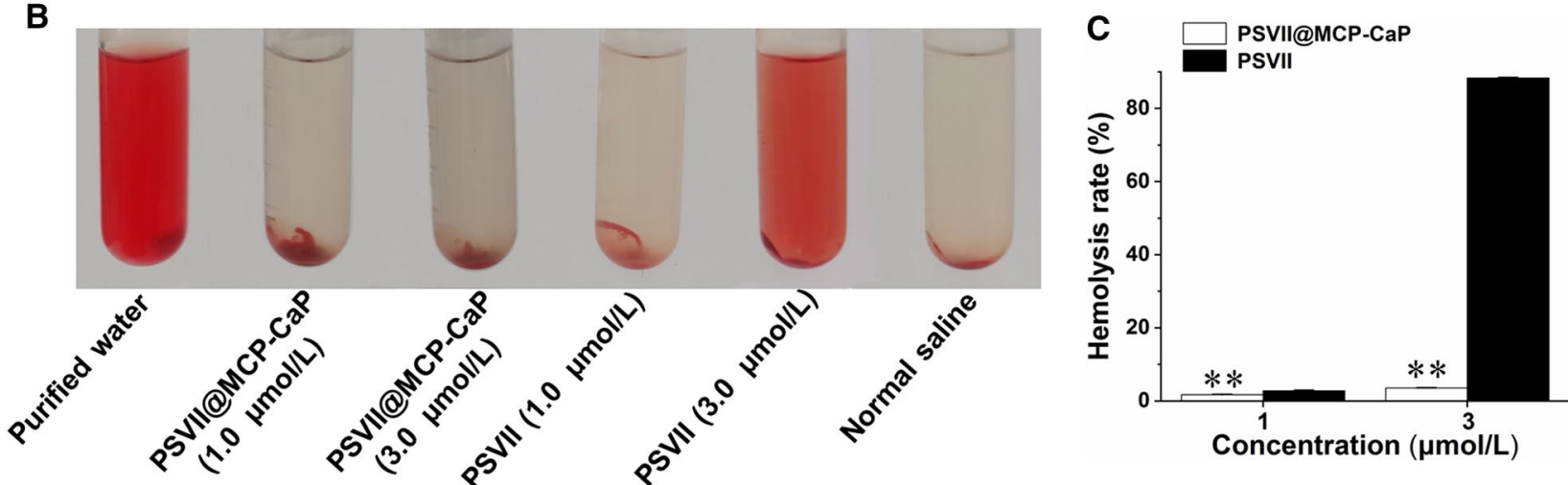

Fig. 3 Hemolysis effect of PSVII@MCP-CaP. A SEM images of blood red cell after incubation with PSVII and PSVII@MCP-CaP. B Hemolysis phenomenon caused by PSVII and PSVII@MCP-CaP. C Statistical results of hemolysis rate. All data are expressed as mean \pm SD ( $n=3$ ). ${ }^{* *} p<0.01$ vs PSVII 


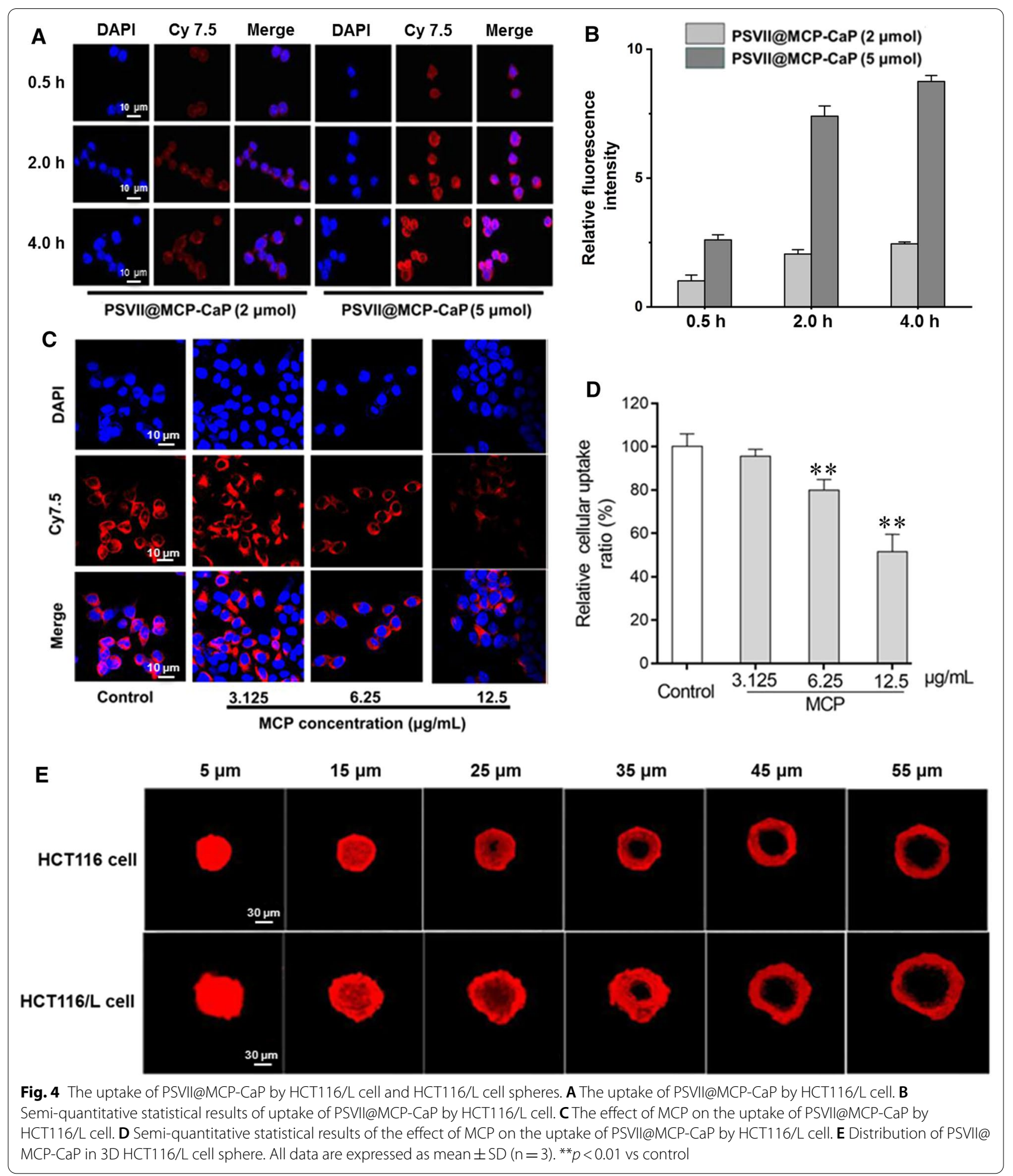

results implied that the uptake of PSVII@MCP-CaP by HCT116/L cells exhibited concentration-dependent and time-dependent manner. When HCT116/L cells were co-incubated with MCP for $1 \mathrm{~h}$ before adding
PSVII@MCP-CaP, the intracellular red fluorescence intensity was significantly reduced. The higher the MCP concentration was, the lower the intensity of intracellular fluorescence became (Fig. 4C, D). This suggested 
that MCP mediated the uptake of PSVII@MCP-CaP by HCT116/L cells.

After incubating with colon cancer cell spheres for $2 \mathrm{~h}$, PSVII@MCP-CaP penetrated into the deep region of 3D colon cancer cell spheres (Fig. 4E). This provided the basis for the excellent anticancer effect of PSVII@MCP$\mathrm{CaP}$ in vivo.

The uptake mechanism of PSVII@MCP-CaP by HCT116/L was further investigated by using LSCM. The results showed that 2-deoxy-D-glucose (2-DG), colchicine and sucrose significantly decreased the uptake of PSVII@MCP-CaP by HCT116/L cells. Methyl- $\beta$ cyclodexin (M- $\beta-C D)$ displayed no significant effect on the uptake of PSVII@MCP-CaP by HCT116/L cells (Additional file 1: Fig. S4). These results demonstrated that HCT116/L cells took up PSVII@MCP-CaP mainly through clathrin mediated endocytosis.

\section{Effects of PSVII@MCP-CaP on proliferation, clone formation, migration and invasion of drug-resistant colon cancer cells}

MTT assay indicated that oxaliplatin significantly inhibited the proliferation of HCT116 cells, HT-29 cell and SW620 cell, while its inhibitory effect on the proliferation of HCT116/L cells was greatly reduced, indicating that HCT116/L cells were resistant to oxaliplatin. Free PSVII and PSVII@MCP-CaP not only inhibited the proliferation of colon cancer cell (including HCT116 cells, HCT116/L cells, HT-29 cell and SW620 cell) in a concentration-dependent manner but also displayed

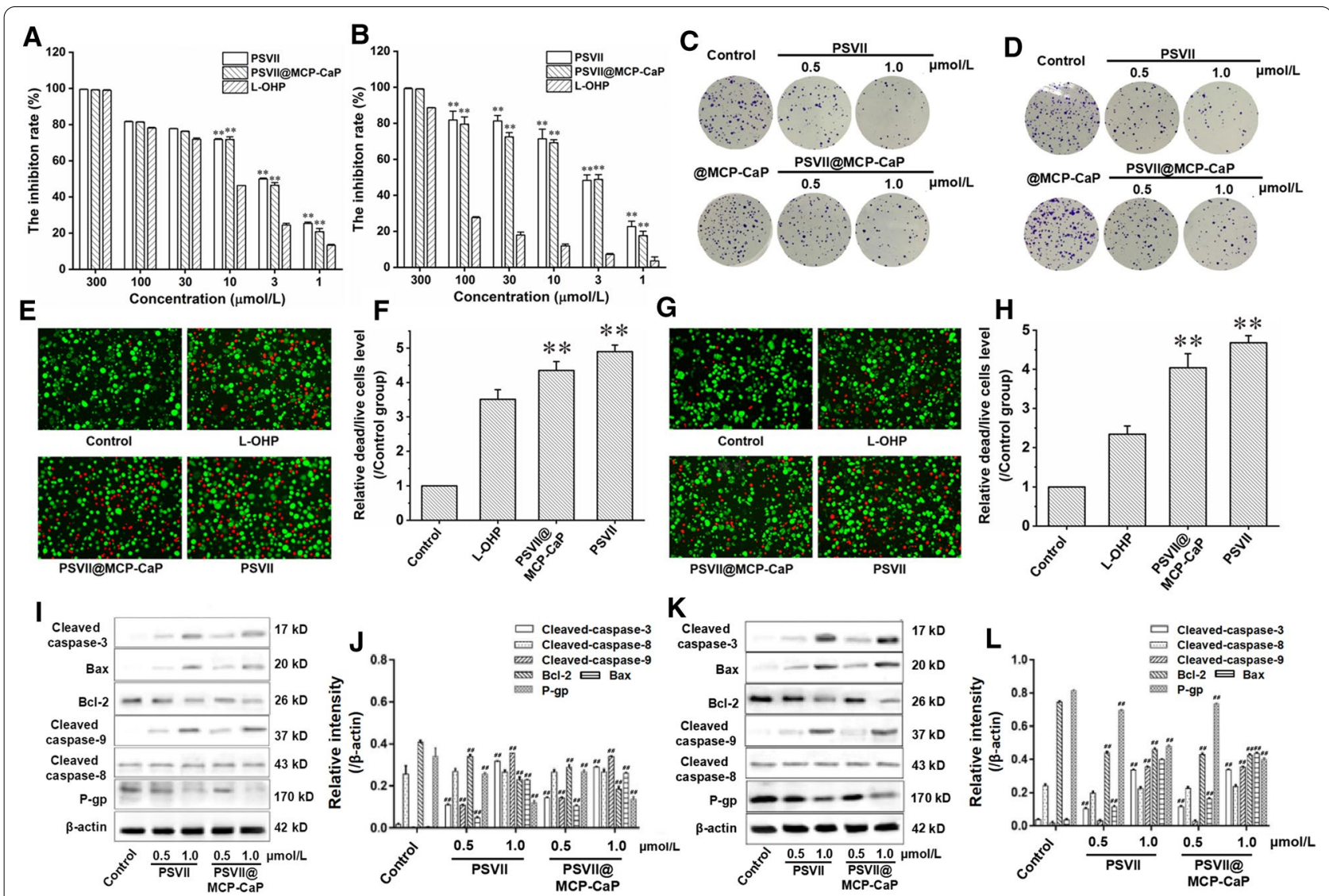

Fig. 5 The inhibitory effect of PSVII@MCP-CaP on HCT116 cell and HCT116/L cell in vitro. A The inhibitory effect of PSVII@MCP-CaP on the proliferation of HCT116 cells. B The inhibitory effect of PSVII@MCP-CaP on the proliferation of HCT116/L cells. C The inhibitory effect of PSVII@ MCP-CaP on the clone formation of HCT1 16 cell. D The inhibitory effect of PSVII@MCP-CaP on the clone formation of HCT116/L cell. E Live/dead cell staining of HCT116 cell. F Semi-quantitative statistical results of the ratio between dead HCT116 cell and live HCT116 cell. G Live/dead cell staining of HCT116/L cell. H Semi-quantitative statistical results of the ratio between dead HCT116/L cell and live HCT116/L cell. IThe effect of PSVII@ MCP-CaP on the expression of apoptosis-related proteins in HCT116 cell. J Semi-quantitative statistical results of the expression of apoptosis-related proteins in HCT1 16 cell. K The effect of PSVII@MCP-CaP on the expression of apoptosis-related proteins in HCT1 16/L cell. L Semi-quantitative statistical results of the expression of apoptosis-related proteins in HCT116/L cell. All data are expressed as mean $\pm S D(n=3) .{ }^{* *} p<0.01$ vs L-OHP; $\# p<0.01$ vs control 
a stronger inhibitory effect than oxaliplatin (Fig. 5A, B; Additional file 1: Fig. S5A, B). Besides, Clone formation experiment showed that in comparison with control group, @MCP-CaP had no significant effect on the clone formation of colon cancer cells, while the clone formation rate of HCT116 cells and HCT116/L cells in PSVII and PSVII@MCP-CaP treatment groups was significantly decreased. The higher the PSVII concentration was, the lower the clone formation rate was (Fig. 5C, D; Additional file 1: Fig. S6A, B). These results indicated that PSVII and PSVII@MCP-CaP inhibited the clone formation of colon cancer cells in a concentration-dependent manner. Furthermore, cell spheres growth experiment indicated that HCT116 cell spheres and HCT116/L cell spheres grew rapidly after treatment with PBS. However, the growth of cell spheres was markedly inhibited after treatment with PSVII and PSVII@MCP-CaP. On the 9th day after drug treatment, the volumes of HCT116 cell spheres and HCT116/L cell spheres in PSVII treatment group were reduced to $74.7 \%$ and $75.2 \%$ of the volume at the beginning of treatment. The volumes of HCT116 cell spheres and HCT116/L cell spheres treated by PSVII@ MCP-CaP reduced to $51.5 \%$ and $56.5 \%$ of the volume at the beginning of treatment (Additional file 1: Fig. S6C, D). The above results demonstrated that PSVII@MCP$\mathrm{CaP}$ inhibited the growth of HCT116 cell spheres and HCT116/L cell spheres. In addition, live/dead cell staining experiment showed that PSVII@MCP-CaP significantly increased the ratio between dead cell and live cell (Fig. 5E-H; Additional file 1: Fig. S5C-F), which was consistent with the results of MTT experiment.

The effects of PSVII@MCP-CaP on the expression of apoptosis-related proteins and P-gp in HCT116 cells and HCT116/L cells were investigated by western blot. The results showed that PSVII and PSVII@MCP-CaP increased Cleaved caspased-3, Cleaved caspased-9 and Bax protein expression, while they decreased $\mathrm{Bcl}-2$ protein expression in HCT116 cells and HCT116/L cells in a concentration-dependent manner as compared to control group (Fig. 5I-L). Furthermore, PSVII and PSVII@ MCP-CaP dose-dependently decreased the expression of P-gp in HCT116/L cells. These results demonstrated that PSVII@MCP-CaP promoted the apoptosis of HCT116 cells and HCT116/L cells through mitochondria-dependent pathway.

The migration and invasion experimental results indicated that in comparison with control group, @MCP$\mathrm{CaP}$ had no significant effect on the migration and invasion rate of HCT116 cell, HCT116/L cell, HT-29 cell and SW620 cell. PSVII and PSVII@MCP-CaP significantly reduced the migration and invasion rate of HCT116 cell, HCT116/L cell, HT-29 cell and SW620 cell (Fig. 6A-H; Additional file 1: Fig. S7A-H). The higher the PSVII concentration was, the lower the migration and invasion rate was. These results demonstrated that PSVII and PSVII@MCP-CaP inhibited the migration and invasion of HCT116 cell, HCT116/L cell, HT-29 cell and SW620 cell in a concentration-dependent manner. Moreover, western blot results showed that protein expression of E-cadherin was higher in PSVII treated group and PSVII@MCP-CaP treated group than in the control group, while protein expression of MMP-9, CD44 and $\mathrm{N}$-cadherin were significantly lower than in the control group (Fig. 6I-L; Additional file 1: Fig. S7I-L). These results indicated that PSVII and PSVII@MCP-CaP inhibited the migration and invasion of colon cancer cells through decreasing MMP-9, CD44 and N-cadherin protein expression.

\section{Biodistribution of PSVII@MCP-CaP in orthotopic drug-resistant colon cancer nude mice}

After administration of Cy7.5-PSVII and Cy7.5-PSVII@ $\mathrm{MCP}-\mathrm{CaP}$ to nude mice with orthotopic drug-resistant colon cancer, fluorescence was mainly distributed in liver, kidney and tumor tissue. As compared with Cy7.5-PSVII, a large amount of fluorescence was mainly distributed in colon cancer tissue at $12 \mathrm{~h}$ and $24 \mathrm{~h}$ after Cy7.5-PSVII@ $\mathrm{MCP}-\mathrm{CaP}$ was administrated (Fig. 7A, B), indicating PSVII@MCP-CaP improved the targeting ability and retention time of PSVII to colon cancer tissue.

\section{In vivo anti orthotopic drug-resistant colon cancer activity of PSVII@MCP-CaP}

On 31th day after drug administration, the mean fluorescence intensity in orthotopic drug-resistant colon cancer tissue showed no significant difference in oxaliplatin treated group and model group (Fig. 7C, D), suggesting that oxaliplatin had weak therapeutic effect on drug-resistant colon cancer. As compared with model group, the mean fluorescence intensity in orthotopic drug-resistant colon cancer tissue in PSVII@MCP-CaP treated group and PSVII treated group were significantly decreased, indicating that PSVII@MCP-CaP and PSVII significantly inhibited the growth of orthotopic drugresistant colon cancer. Moreover, the inhibitory effect of PSVII@MCP-CaP on the growth of orthotopic drugresistant colon cancer was stronger than that of PSVII. In addition, the images and tumor volume of orthotopic drug-resistant colon cancer tissue are showing in Fig. 7E, F. Compared with model group, PSVII@MCP-CaP and PSVII significantly reduced the tumor volume of orthotopic drug-resistant colon cancer tissue, which was consistent with the results observed by in vivo bioluminescence imager.

H\&E staining of orthotopic drug-resistant colon cancer tissue showed that the nucleus was large and 


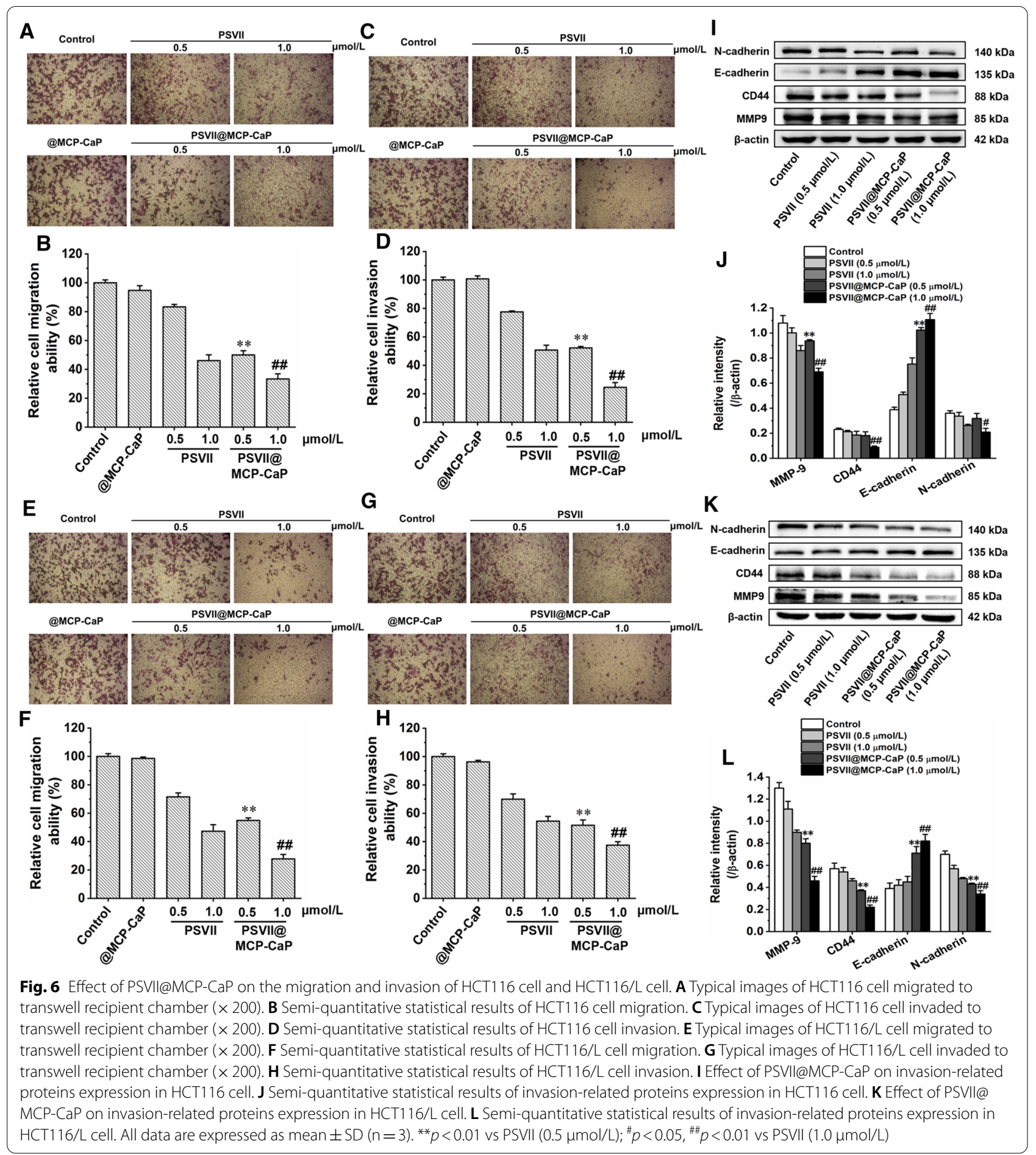

dense, and there was connective tissue in the stroma of drug-resistant colon cancer tissue in the model group. However, in oxaliplatin and PSVII treatment groups, nuclear pyknosis was found in some of drug-resistant colon cancer tissues. While in PSVII@MCP-CaP treatment group, there were obvious nuclear pyknosis and nucleus miniaturization in drug-resistant colon cancer tissues, and the number of cancer cells was significantly reduced (Fig. 8A). These results indicated that PSVII@ $\mathrm{MCP}-\mathrm{CaP}$ displayed significant toxicity on orthotopic drug-resistant colon cancer cells and improved the anti-tumor activity of PSVII. 


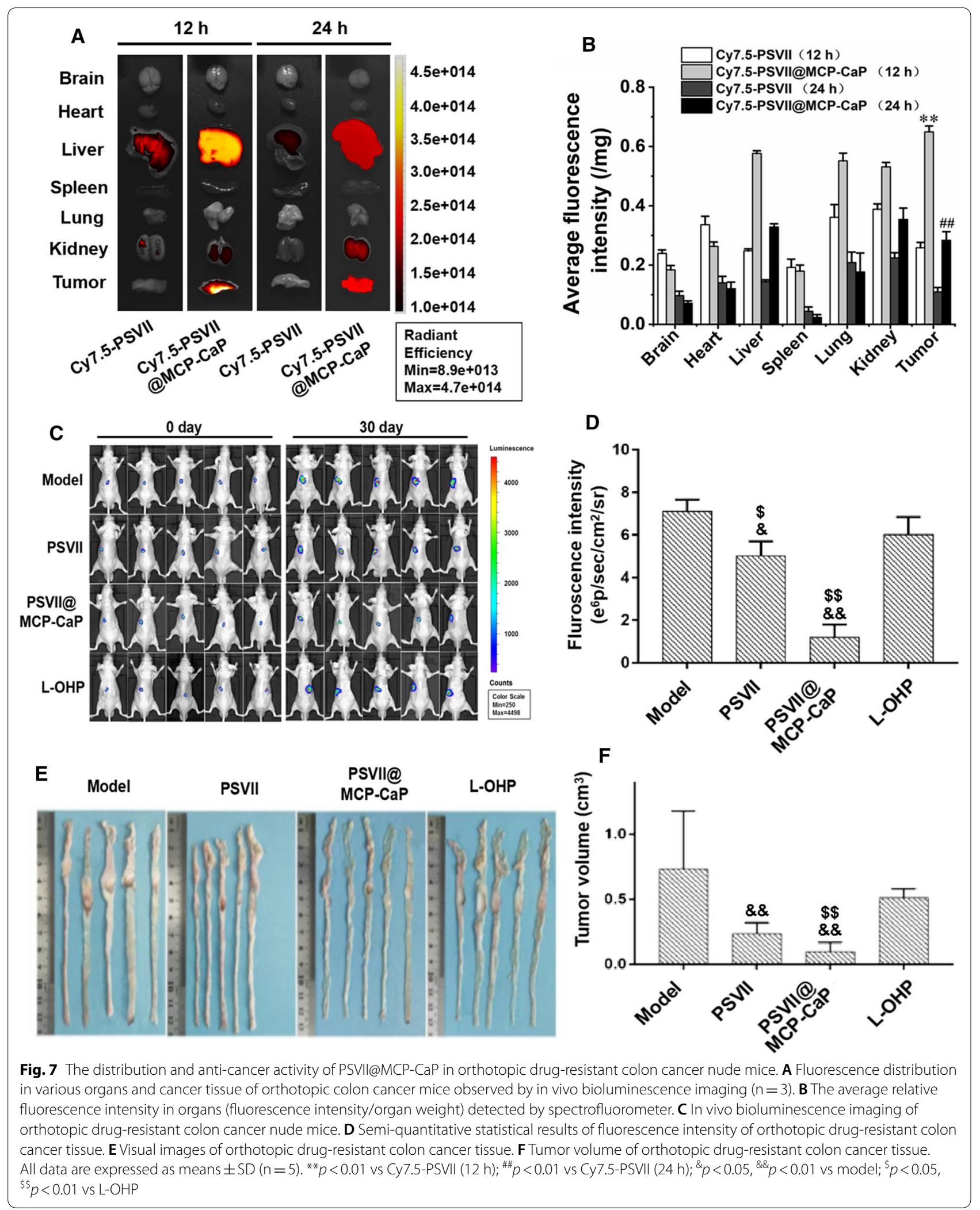




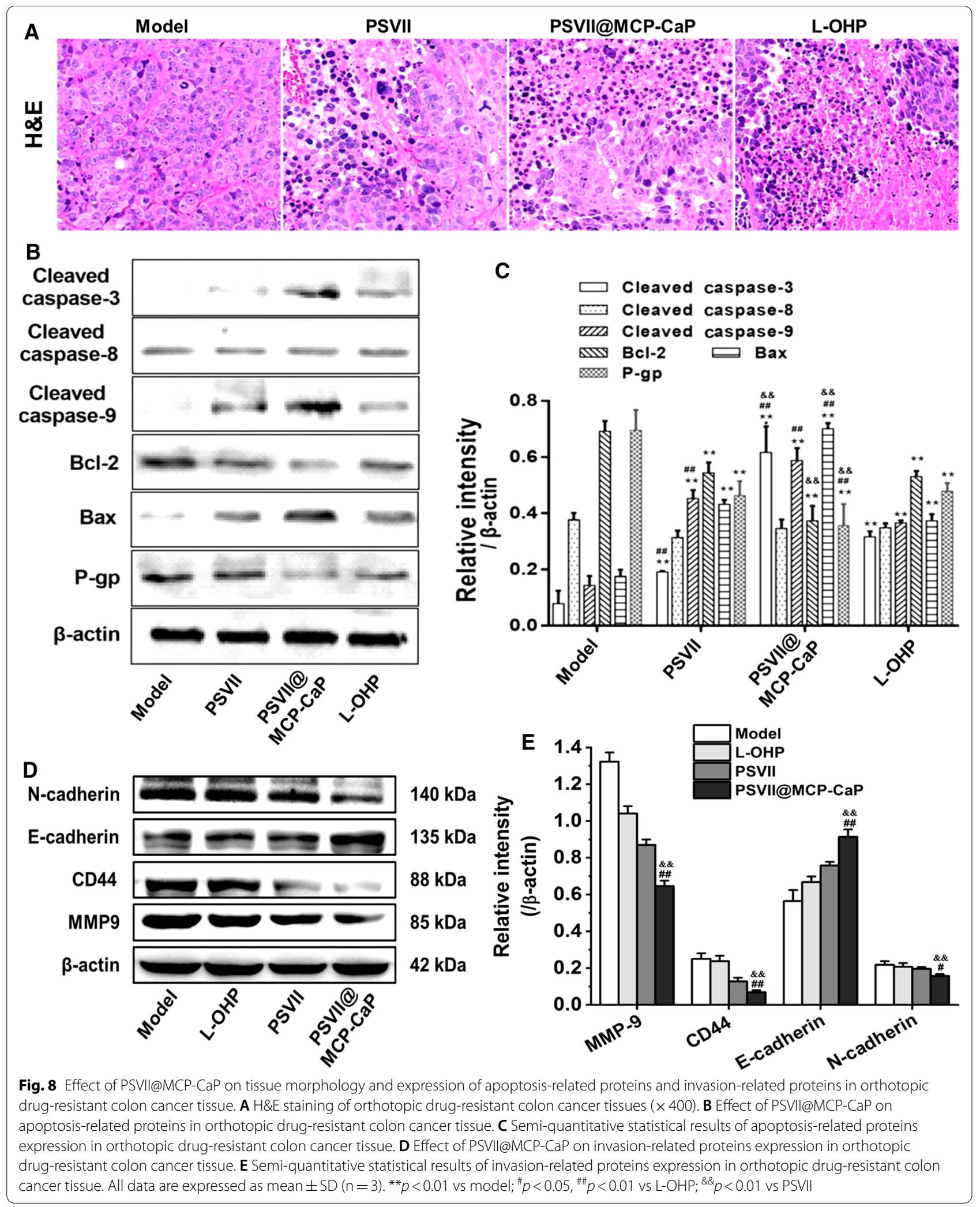




\section{Effect of PSVII@MCP-CaP on expression of apoptosis-related and invasion-related proteins in orthotopic drug-resistant colon cancer tissue}

Western blot results of orthotopic drug-resistant colon cancer tissues are showing in Fig. 8B, C. As compared with model group, the protein expressions of P-gp and Bcl-2 in orthotopic resistant colon cancer tissues were significantly decreased after treatment with PSVII and PSVII@MCP-CaP, and the protein expressions of Cleaved caspase-3, Cleaved caspase- 9 and Bax were significantly increased. These results indicated that PSVII and PSVII@ $\mathrm{MCP}-\mathrm{CaP}$ induced apoptosis of drug-resistant colon cancer tissue and subsequently inhibited the growth of drugresistant colon cancer through mitochondria-dependent programmed death pathway. The protein expressions of Cleaved caspase-3, Cleaved caspase- 9 and Bax were significantly higher in PSVII@MCP-CaP treated group than in PSVII treated group, indicating PSVII@MCP-CaP displayed much stronger capability in inducing apoptosis of drug-resistant colon cancer tissue than that of PSVII. In addition, PSVII@MCP-CaP significantly reduced the protein expressions of CD44, MMP-9 and N-cadherin in drug-resistant colon cancer tissue, while the expression of E-cadherin was increased (Fig. 8D, E). These results demonstrated that PSVII@MCP-CaP inhibited the migration and invasion of colon cancer cells by decreasing the protein expression of CD44, MMP-9 and N-cadherin, while increasing the protein expression of E-cadherin.

\section{In vivo safety of PSVII@MCP-CaP}

The body weights of cancer-bearing nude mice are showing in Fig. 9A. As compared with model group, the body weight of cancer-bearing nude mice in PSVII@MCP-CaP treated groups showed no significant decline. H\&E staining showed that there were vacuoles and granule degeneration in renal tubular epithelial cells of cancer-bearing nude mice in oxaliplatin treated mice (Fig. 9B), which indicated that oxaliplatin caused certain toxicity to kidney of cancer-bearing nude mice. Besides, the space of spleen tissue in PSVII treated group was enlarged and the nucleus size was irregular in cancer-bearing nude mice. There was granule degeneration of renal tubular epithelial cells in renal tissue. These results suggested that PSVII led to certain toxicity on spleen and kidney in cancer-bearing nude mice. There were not significant histopathological changes in organs in PSVII@MCP-CaP treated cancer-bearing nude mice.

\section{Discussion}

PSVII displays strong anticancer activity. However, the structure of PSVII is similar to that of surfactants and has strong hemolytic activity and emulsification, which

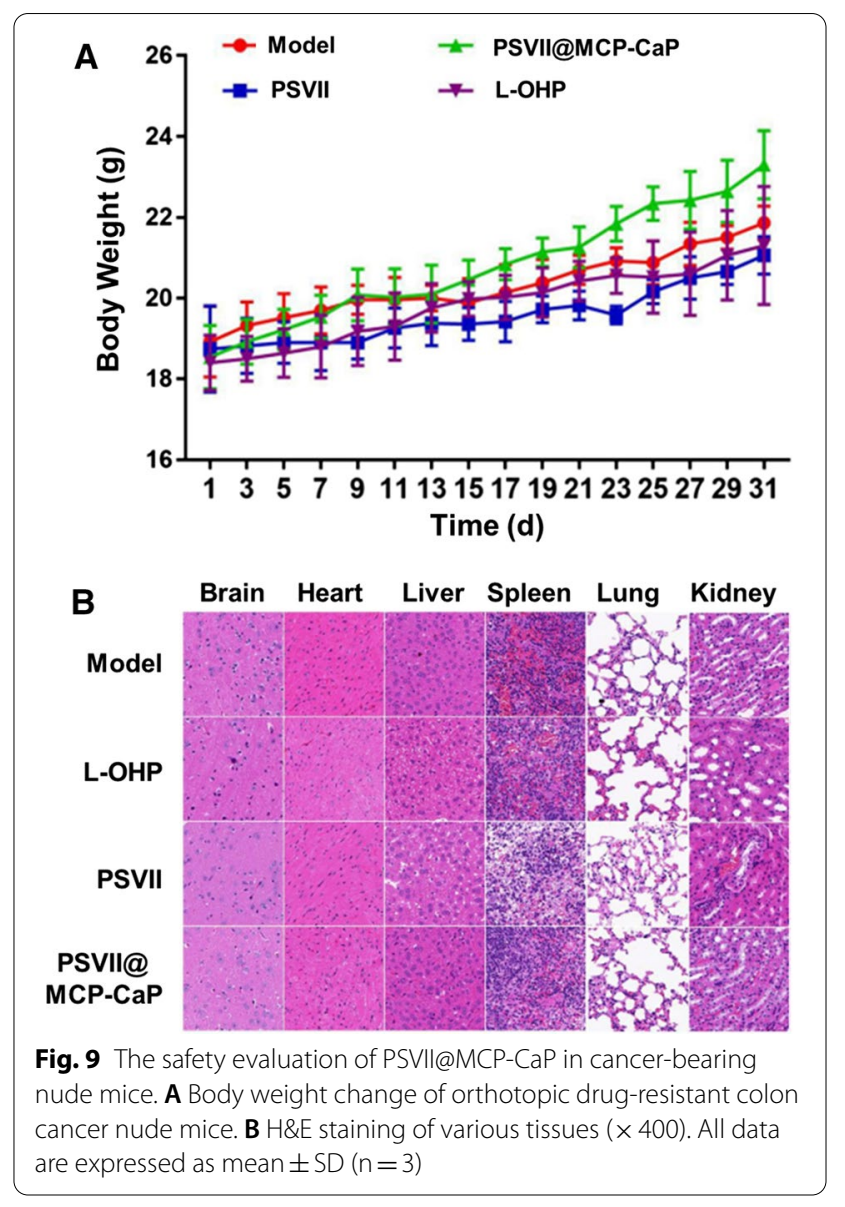

can rupture red blood cells and bring serious damage to human body. This greatly limits its clinical application. PSVII can bind to phospholipid bilayer on the erythrocyte membrane, resulting in changes in the permeability of the membrane [18-20]. This further leads to dilation and disintegration of red blood cells. Moreover, PSVII is insoluble compound both in water and fat. The molecular structure of PSVII does not contain functional groups binding calcium phosphate, so PSVII can't be directly loaded into $\mathrm{CaP}$ nanoparticles by precipitation method in water. We found that CM- $\beta-C D$ and PSVII could form inclusion complex in water, and CM- $\beta-C D$ could bind calcium phosphate. Therefore, by using $C M-\beta-C D$ and PSVII inclusion complex, PSVII could be embedded in $\mathrm{CaP}$ nanoparticles. This research explored a new method to prepare $\mathrm{CaP}$ nanoparticles loaded with a fat and water insoluble compound in water.

Finding new specific targets that can be recognized by drug delivery system is a hot and difficult topic in drug delivery system research. We found that Gal-3 was highly expressed on the membrane of colon cancer cells, which was consistent with previous reports [21, 22]. Immunofluorescence experimental results also indicated that a 
large amount of Gal-3 expressed in colon cancer tissue. Therefore, Gal-3 can be used as a specific binding target for colon cancer targeting drug delivery system [23, 24]. Furthermore, MCP is the hydrolyzed product of citrus pectin. The molecular weight and esterification degree of MCP are lower than that of citrus pectin. Previous studies have confirmed that MCP can block Gal-3 site on the surface of tumor cells, inhibiting the aggregation of cancer cells in blood circulation, and thus reducing cancer metastasis [25-27]. In addition, by blocking Gal-3 site, MCP inhibits cancer cells to take up nutrients from blood vessels, further slowing cancer tissue growth. Thus, MCP is a multi-function targeting ligand for colon cancer-specific drug delivery system.

The results of LSCM indicated that PSVII@MCP-CaP was taken up by drug-resistant colon cancer cells in timedependent manner. When drug-resistant colon cancer cells were co-incubated with different concentrations of MCP, the uptake of PSVII@MCP-CaP by drug-resistant colon cancer cells was significantly reduced. In addition, the uptake experimental results also demonstrated that PSVII@MCP-CaP was taken up by HCT116/L cells mainly through clathrin mediated endocytosis. These results indicated that MCP mediated the uptake of PSVII@MCP-CaP in drug-resistant colon cancer cells. In vivo experimental results also showed that a large amount of PSVII@MCP-CaP accumulated in orthotopic drug-resistant colon cancer tissue, and PSVII@MCP$\mathrm{CaP}$ penetrated into the deeper region of orthotopic drug-resistant colon cancer tissue. These results implied that PSVII@MCP-CaP delivered PSVII to drug-resistant colon cells in an active manner through interaction between Gal-3 and MCP.

$\mathrm{CaP}$ nanoparticle is an excellent drug delivery system with good safety. However, it is very difficult to prepare stabilized $\mathrm{CaP}$ nanoparticles. In order to improve the stability of $\mathrm{CaP}$ nanoparticles, researchers usually use chitosan, hyaluronic acid and other stabilizer during preparation of $\mathrm{CaP}$ nanoparticles in water, so as to inhibit the size growth of $\mathrm{CaP}$ nanoparticles and the transformation of CaP nanoparticles into calcium phosphate crystals $[28,29]$. We have found that MCP contains a large number of carboxyl groups, which can bind with $\mathrm{Ca}^{2+}$ in calcium phosphate under alkaline conditions to increase the stability of $\mathrm{CaP}$ nanoparticles. The experimental results showed that MCP modified CaP nanoparticles (PSVII@ $\mathrm{MCP}-\mathrm{CaP}$ ) could be stored stably in deionized water for 18 days.

There are two main apoptosis pathways, including death receptor-mediated apoptosis pathway and mitochondria-mediated apoptosis pathway [30, 31]. The death receptor pathway mainly promotes the production of caspase-8, and then activates the downstream caspase factor, thus initiating the apoptosis process dependent on the caspase-enzyme cascade [32]. Mitochondrial apoptosis mainly regulates the $\mathrm{Bcl}-2$ protein family [33]. Studies have shown that the higher the $\mathrm{Bcl}-2 / \mathrm{Bax}$ ratio is, the stronger the mitochondrial membrane permeability became, which promotes the release of $\mathrm{CytC}$, and then activates caspase- 3 and finally causes cell apoptosis [34]. The experimental results indicated that PSVII@ $\mathrm{MCP}-\mathrm{CaP}$ reduced $\mathrm{Bcl}-2$ expression and increased Bax, Cleaved caspased-9 and Cleaved caspased-3 expression in drug-resistant colon cancer tissue. These results demonstrated that PSVII@MCP-CaP promoted the apoptosis of drug-resistant colon cancer cells through mitochondria-mediated apoptosis pathway.

Local recurrence and metastasis are the main causes of death in colon cancer patients [35]. Studies have shown that E-cadherin is a key molecule to maintain the adhesion between cancer cells [36-38]. Inhibiting the expression of E-cadherin can reduce the adhesion between cancer cells and lead to the shedding of cancer cells from primary cancer tissue, which induces the metastasis of colon cancer $[39,40]$. In addition, MMP-9 can degrade E-cadherin, subsequently reduce the adhesion between cancer cells [41, 42]. Finally, the invasion and metastasis of cancer cells are promoted. The experimental results showed that PSVII@MCP-CaP inhibited invasion and migration of drug-resistant colon cancer cells in a concentration-dependent manner. Further studies indicated that PSVII@MCP-CaP significantly increased the expression of E-cadherin and decreased the expression of N-cadherin and MMP-9 in drug-resistant colon cancer cells and orthotopic drug-resistant colon cancer tissue, which subsequently enhanced the adhesion between cancer cells in colon cancer tissue. Thus, PSVII@MCP-CaP inhibited the invasion and migration of drug-resistant colon cancer.

\section{Conclusion}

PSVII@MCP-CaP significantly reduced the hemolysis effect of PSVII. PSVII was successfully encapsulated in $\mathrm{CaP}$ nanoparticles through formatting a $\mathrm{CM}-\beta-\mathrm{CD}$ inclusion complex. By specific accumulating in orthotopic drug-resistant colon cancer tissue, PSVII@MCP-CaP effectively inhibited the growth of orthotopic drug-resistant colon cancer in nude mice. PSVII@MCP-CaP promoted the apoptosis of drug-resistant colon cancer cells through mitochondria-mediated apoptosis pathway. PSVII@MCP-CaP also significantly inhibited the invasion and migration of drug-resistant colon cancer cells by increasing the expression of E-cadherin and reducing the expression of N-cadherin and MMP-9. 


\section{Abbreviations}

PSVII: Paris saponin VII; MCP: Modified citrus pectin; CaP: Calcium phosphate nanoparticles; ACP: Amorphous calcium phosphate; $C M-\beta-C D$ : Carboxymethyl- $\beta$-cyclodextrin; Gal-3: Galectin-3; FBS: Foetal bovine serum; DAPI: 4',6-Diamidino-2-phenylindole dihydrochloride; L-OHP: Oxaliplatin; 5-Fu: 5-Fluorouracil; MTT: 3-(4,5-Dimethylthiazol-2-yl)-2,5-diphenyltetrazolium bromide; HCT116/Fu cells: 5-Fu-resistant HCT116 cells; HCT116/L cells: L-OHPresistant HCT116 cells; SDS-PAGE: Sulfate-polyacrylamide gel electrophoresis; PBS: Phosphate buffer saline; HR: Hemolysis rate; PDI: Polydispersity index DTG: Derivative thermogravimetry; XPS: X-ray photoelectron spectrometer; LSCM: Laser scanning confocal microscopy; SEM: Scanning electron microscope; TEM: Transmission electron microscope; HPLC: High-performance liquid chromatography.

\section{Supplementary Information}

The online version contains supplementary material available at https://doi. org/10.1186/s12951-021-01115-9.

Additional file 1: Figure S1 Immunofluorescence staining of Gal-3 in the colon tissue of normal nude mouse. Blue: nucleus; red: Gal-3 protein. Figure S2. XPS analysis of phosphorus (A), calcium (B), carbon (C), and oxygen (D) in PSVII@MCP-CaP. Figure S3. Thermogravimetric analysis of calcium phosphate powder (A),MCP (B),PSVII@CM- $\beta$-CD inclusion compound (C), @MCP-CaP (D), and PSVII@MCP-CaP (E). Figure S4. The cellular uptake mechanism of PSVII@MCP-CaP by HCT116/L cell. A The effect of uptake inhibitor on the uptake of PSVII@MCP-CaP by HCT116/L cell observed via LSCM. B Semi-quantitative analysis results of PSVII@ MCP-CaP uptake by HCT116/L cell. All data are expressed as mean \pm SD $(\mathrm{n}=3) .{ }^{*} p<0.01$ vs control. Figure S5. The inhibitory effect of PSVII@ MCP-CaP on proliferation of HT-29 cell and SW620 cell in vitro. A The inhibitory effect of PSVII@MCP-CaP on the proliferation of HT-29 cell. B The inhibitory effect of PSVII@MCP-CaP on the proliferation of SW620 cell. C Live/dead cell staining of HT-29 cell. D Semi-quantitative statistical results of the ratio between dead HT-29 cell and live HT-29 cell. E Live/dead cell staining of SW620 cell. F Semi-quantitative statistical results of the ratio between dead SW620 cell and live SW620 cell. All data are expressed as mean \pm SD $(n=5) .{ }^{* *} p<0.01$ vs L-OHP. Figure S6. The statistical results of cell clone formation and growth of cell spheres. A Semi-quantitative statistical results of HCT116 cell clone formation. $\mathbf{B}$ Semi-quantitative statistical results of HCT116/L cell clone formation. CThe effect of PSVII@MCP-CaP on the growth of HCT116 cell spheres. D The effect of PSVII@MCP-CaP on the growth of HCT116/L cell spheres. All data are expressed as mean \pm SD $(\mathrm{n}=3) .{ }^{* *} p<0.01$ vs control: \#\# $p<0.01$ vs PBS. Figure S7. Effect of PSVII@ MCP-CaP on the migration and invasion of HT-29 cell and SW620 cell. A Typical images of HT-29 cell migrated to transwell recipient chamber (× 200). B Semi-quantitative statistical results of HT-29 cell migration. C Typical images of HT-29 cell invaded to transwell recipient chamber ( $\times$ 200). D Semi-quantitative statistical results of HT-29 cell invasion. E Typical images of SW620 cell migrated to transwell recipient chamber (× 200). F Semi-quantitative statistical results of SW620 cell migration. G Typical images of SW620 cell invaded to transwell recipient chamber (× 200). H Semi-quantitative statistical results of SW620 cell invasion. I Effect of PSVII@MCP-CaP on invasion-related proteins expression in HT-29 cell. J Semi-quantitative statistical results of invasion-related proteins expression in HT-29 cell. K Effect of PSVII@MCP-CaP on invasion-related proteins expression in SW620 cell. L Semi-quantitative statistical results of invasion-related proteins expression in SW620 cell. All data are expressed as means $\pm \mathrm{SD}(\mathrm{n}=3) .{ }^{*} p<0.05,{ }^{*} p<0.01$ vs PSVII $(0.5 \mu \mathrm{mol} / \mathrm{L}) ;{ }^{*} p<0.05$ \#\# $p<0.01$ vs PSVII $(1.0 \mu \mathrm{mol} / \mathrm{L})$

\section{Acknowledgements}

Not applicable.

\section{Authors' contributions}

SB, YS, and CJ performed the experiments and analysis. YC, WY, ML, and QJ performed investigation and visualization. BZ, QM, and DL performed conceptualization and methodology. SZ performed project administration and funding acquisition. All authors read and approved the final manuscript.

\section{Funding}

This research was supported by the National Nature Science Foundation (No. 82073775), Shaanxi Province Key Research and Development Projects of China (2021ZDLSF03-08) and Innovation Capability Support Plan of Shaanxi Province (No. 2020TD-041).

\section{Availability of data and materials}

All data generated or analyzed during this study are included in this published article and its additional information file.

\section{Declarations}

\section{Ethics approval and consent to participate}

All the animals received care in terms of the guidelines for the Care and Use of Laboratory Animals and the animal experiments were approved by the Air Force Medical University Institutional Animal Care and Utilization Committee (No: IACUC-20200901)

\section{Consent for publication}

Not applicable.

\section{Competing interests}

There is no competing interest.

\section{Author details}

${ }^{1}$ Department of Pharmaceutics, School of Pharmacy, Air Force Medical University, Changle West Road 169, Xi'an 710032, Shaanxi, China. ${ }^{2}$ Key Laboratory of Gastrointestinal Pharmacology of Chinese Materia Medica of the State Administration of Traditional Chinese Medicine, Department of Pharmacology, School of Pharmacy, Air Force Medical University, Xi'an 710032, China.

Received: 24 August 2021 Accepted: 2 November 2021

Published online: 17 November 2021

\section{References}

1. Zhang MM, Wang D, Lu F, Zhao R, Ye X, He L, Ai L, Wu CJ. Identification of the active substances and mechanisms of ginger for the treatment of colon cancer based on network pharmacology and molecular docking. BioData Min. 2021;14:1

2. Han H, Li HM, Zhou J. Long non-coding RNA MIR503HG inhibits the proliferation, migration and invasion of colon cancer cells via miR-107/ Par4 axis. Exp Cell Res. 2020;395:112205.

3. Brenner $\mathrm{H}$, Chen $\mathrm{C}$. The colorectal cancer epidemic: challenges and opportunities for primary, secondary and tertiary prevention. $\mathrm{Br} J$ Cancer. 2018;119:785-92.

4. Vellinga TT, Borovski T, de Boer VC, Fatrai S, van Schelven S, Trumpi K, Verheem A, Snoeren N, Emmink BL, Koster J, et al. SIRT1/PGC1a-dependent increase in oxidative phosphorylation supports chemotherapy resistance of colon cancer. Clin Cancer Res. 2015;21:2870-9.

5. Zhou HP, Sun Y, Zheng HN, Fan L, Mei QB, Tang Y, Duan XQ, Li YH. Paris saponin VII extracted from trillium tschonoskii suppresses proliferation and induces apoptosis of human colorectal cancer cells. J Ethnopharmacol. 2019;239:111903.

6. Zhang X, Sun Y, Cheng Y, Ye WL, Zhang BL, Mei QB, Zhou SY. Biopharmaceutics classification evaluation for Paris saponin VII. Chin J Nat Med. 2020;18:714-20.

7. Wey K, Schirrmann R, Diesing D, Lang S, Brandau S, Hansen S, Epple M. Coating of cochlear implant electrodes with bioactive DNA-loaded calcium phosphate nanoparticles for the local transfection of stimulatory proteins. Biomaterials. 2021;276:121009.

8. Dorozhkin SV. Functionalized calcium orthophosphates(CaPO4) and their biomedical applications. J Mater Chem B. 2019;7:7471-89.

9. Lu JY, Yu HJ, Chen CZ. Biological properties of calcium phosphate biomaterials for bone repair: a review. RSC Adv. 2018;8:2015-33.

10. Sokolova V, Epple M. Biological and medical applications of calcium phosphate nanoparticles. Chemistry. 2021:27:7471-88.

11. Liu Y, Huang L. Preparation and characterization of siRNA-loaded liposomes. Methods Mol Biol. 2021;2282:159-69. 
12. Xu HP, Lin D, Zhang B, Huo YS, Lin SF, Liu C, Chen C, Wang CL. Supramolecular self-assembly of a hybrid 'hyalurosome' for targeted photothermal therapy in non-small cell lung cancer. Drug Deliv. 2020;27:378-86.

13. Yang Q, Liu DZ, Liu M, Ji QF, Mei QB, Cheng Y, Zhou SY. Bone-targeted calcium phosphate-polymer hybrid nanoparticle co-deliver zoledronate and docetaxel to treat bone metastasis of prostate cancer. J Pharm Sci. 2021;110:876-87.

14. Li YB, Wiliana T, Tam KC. Synthesis of amorphous calcium phosphate using various types of cyclodextrins. Mater Res Bull. 2007;42:820-7.

15. Balakrishnan B, Subramanian S, Mallia MB, Repaka K, Kaur S, Chandan R, Bhardwaj P, Dash A, Banerjee R. Multifunctional core-shell glyconanoparticles for galectin-3-targeted, trigger-responsive combination chemotherapy. Biomacromol. 2020;21:2645-60.

16. Wang SJ, Liu HF, Xin J, Rahmanzadeh R, Wang J, Yao CP, Zhang ZX. Chlorin-based photoactivable galectin-3-inhibitor nanoliposome for enhanced photodynamic therapy and NK cell-related immunity in melanoma. ACS Appl Mater Interfaces. 2019;11:41829-41.

17. Eliaz I, Raz A. Pleiotropic effects of modified citrus pectin. Nutrients. 2019;11:2619.

18. Liu Z, Gao W, Jing S, Zhang Y, Man S, Wang Y, Zhang J, Liu C. Correlation among cytotoxicity, hemolytic activity and the composition of steroidal saponins from Paris L. J Ethnopharmacol. 2013;149:422-30.

19. Melzig MF, Bader G, Loose R. Investigations of the mechanism of membrane activity of selected triterpenoid saponins. Planta Med. 2001;67:43-8.

20. Baumann E, Stoya G, Völkner A, Richter W, Lemke C, Linss W. Hemolysis of human erythrocytes with saponin affects the membrane structure. Acta Histochem. 2000;102:21-35.

21. Huang ZL, Ai ZN, Li N, Xi HF, Gao XC, Wang F, Tan XJ, Liu HY. Over expression of galectin-3 associates with short-term poor prognosis in stage II colon cancer. Cancer Biomark. 2016:17:445-55.

22. Wang HS, Wang LH. The expression and significance of Gal-3 and MUC1 in colorectal cancer and colon cancer. Onco Targets Ther. 2015:8:1893-8.

23. Dong R, Zhang M, Hu QY, Zheng S, Soh A, Zheng YJ, Yuan H. Galectin-3 as a novel biomarker for disease diagnosis and a target for therapy (Review). Int J Mol Med. 2018;41:599-614.

24. Leclere L, van Cutsem P, Michiels C. Anti-cancer activities of pH- or heatmodified pectin. Front Pharmacol. 2013:4:128.

25. Ahmed H, AlSadek DM. Galectin-3 as a potential target to prevent cancer metastasis. Clin Med Insights Oncol. 2015;9:113-21.

26. Glinsky W, Raz A. Modified citrus pectin anti-metastatic properties: one bullet, multiple targets. Carbohydr Res. 2009;344:1788-91.

27. Glinskii OV, Huxley VH, Glinsky GV, Pienta KJ, Raz A, Glinsky V. Mechanical entrapment is insufficient and intercellular adhesion is essential for metastatic cell arrest in distant organs. Neoplasia. 2005;7:522-7.

28. Luo C, Wu S, Li J, Li X, Yang P, Li G. Chitosan/calcium phosphate flower-like microparticles as carriers for drug delivery platform. Int J Biol Macromol. 2020;155:174-83.

29. Chu WJ, Huang YJ, Yang CZ, Liao Y, Zhang X, Yan M, Cui S, Zhao C. Calcium phosphate nanoparticles functionalized with alendronate-conjugated polyethylene glycol (peg) for the treatment of bone metastasis. Int J Pharm. 2017;516:352-63.
30. Gao X, Li XF, Mu JJ, Ho CT, Su JY, Zhang YT, Lin XR, Chen ZZ, Li B, Xie YZ. Preparation, physicochemical characterization, and anti-proliferation of selenium nanoparticles stabilized by Polyporus umbellatus polysaccharide. Int J Biol Macromol. 2020;152:605-15.

31. König C, Hillert-Richter LK, Ivanisenko NV, Ivanisenko VA, Lavrik IN. Pharmacological targeting of c-FLIPL and Bcl-2 family members promotes apoptosis in CD95L-resistant cells. Sci Rep. 2020;10:20823.

32. Li H, Niu N, Yang J, Dong F, Zhang T, Li S, Zhao W. Nuclear respiratory factor 1 protects $\mathrm{H} 9 \mathrm{C} 2$ cells against hypoxia-induced apoptosis via the death receptor pathway and mitochondrial pathway. Cell Biol Int. 2021;45:1784-96.

33. Dadsena S, King LE, García-Sáez AJ. Apoptosis regulation at the mitochondria membrane level. Biochim Biophys Acta Biomembr. 2021;1863:183716.

34. Safaeinejad F, Asadi S, Ghafghazi S, Niknejad H. The synergistic antiapoptosis effects of amniotic epithelial stem cell conditioned medium and ponesimod on the oligodendrocyte cells. Front Pharmacol. 2021;12:691099.

35. Wang K, Song W, Shen Y, Wang H, Fan Z. LncRNA KLK8 modulates stem cell characteristics in colon cancer. Pathol Res Pract. 2021;224:153437.

36. Alsharif S, Sharma P, Bursch K, Milliken R, Lam V, Fallatah A, Phan T, Collins M, Dohlman P, Tiufekchiev S. Keratin 19 maintains E-cadherin localization at the cell surface and stabilizes cell-cell adhesion of MCF7 cells. Cell Adhes Migr. 2021;15:1-17.

37. Eslami Amirabadi H, Tuerlings M, Hollestelle A, SahebAli S, Luttge R, van Donkelaar CC, Martens JWM, den Toonder JMJ. Characterizing the invasion of different breast cancer cell lines with distinct E-cadherin status in 3D using a microfluidic system. Biomed Microdevices. 2019;21:101.

38. Beetham $H$, Chen A, Telford BJ, Single A, Jarman KE, Lackovic K, Luxenburger A, Guilford P. A high-throughput screen to identify novel synthetic lethal compounds for the treatment of E-cadherin-deficient cells. Sci Rep. 2019;9:12511.

39. Roque R, Costa Sousa F, Figueiredo-Dias M. Epithelial-mesenchymal interconversions in ovarian cancer: the levels and functions of E-cadherin in intraabdominal dissemination. Oncol Rev. 2020;14:475.

40. Otake S, Itoh Y, Omata C, Saitoh M, Miyazawa K. ZEB1 and oncogenic Ras constitute a regulatory switch for stimulus-dependent E-cadherin downregulation. Cancer Sci. 2021;112:205-16.

41. Boukhedouni N, Martins C, Darrigade AS, Drullion C, Rambert J, Barrault C, Garnier J, Jacquemin C, Thiolat D, Lucchese F, et al. Type-1 cytokines regulate MMP-9 production and E-cadherin disruption to promote melanocyte loss in vitiligo. JCI Insight. 2020;5:e133772.

42. Symowicz J, Adley BP, Gleason KJ, Johnson JJ, Ghosh S, Fishman DA, Hudson LG, Stack MS. Engagement of collagen-binding integrins promotes matrix metalloproteinase-9-dependent E-cadherin ectodomain shedding in ovarian carcinoma cells. Cancer Res. 2007;67:2030-9.

\section{Publisher's Note}

Springer Nature remains neutral with regard to jurisdictional claims in published maps and institutional affiliations.
Ready to submit your research? Choose BMC and benefit from:

- fast, convenient online submission

- thorough peer review by experienced researchers in your field

- rapid publication on acceptance

- support for research data, including large and complex data types

- gold Open Access which fosters wider collaboration and increased citations

- maximum visibility for your research: over $100 \mathrm{M}$ website views per year

At BMC, research is always in progress.

Learn more biomedcentral.com/submissions 